\title{
Role of resolution in regional climate change projections over China
}

\author{
Ying $\mathrm{Shi}^{1} \cdot$ Guiling Wang ${ }^{2} \cdot$ Xuejie Gao ${ }^{3,4}$
}

Received: 10 January 2017 / Accepted: 16 November 2017 / Published online: 21 November 2017

(c) The Author(s) 2017. This article is an open access publication

\begin{abstract}
This paper investigates the sensitivity of projected future climate changes over China to the horizontal resolution of a regional climate model RegCM4.4 (RegCM), using RCP8.5 as an example. Model validation shows that RegCM performs better in reproducing the spatial distribution and magnitude of present-day temperature, precipitation and climate extremes than the driving global climate model HadGEM2-ES (HadGEM, at $1.875^{\circ} \times 1.25^{\circ}$ degree resolution), but little difference is found between the simulations at 50 and $25 \mathrm{~km}$ resolutions. Comparison with observational data at different resolutions confirmed the added value of the RCM and finer model resolutions in better capturing the probability distribution of precipitation. However, HadGEM and RegCM at both resolutions project a similar pattern of significant future warming during both winter and summer, and a similar pattern of winter precipitation changes including dominant increase in most areas of northern China and little change or decrease in the southern part. Projected precipitation changes in summer diverge among the three models, especially over eastern China, with a general increase in HadGEM, little change in RegCM at $50 \mathrm{~km}$, and a mix of increase and decrease in RegCM at $25 \mathrm{~km}$ resolution. Changes of temperature-related extremes (annual total number of daily maximum temperature $>25^{\circ} \mathrm{C}$, the maximum value of daily maximum temperature, the minimum value of daily minimum temperature in the three simulations especially in the two RegCM simulations are very similar to each other; so are the precipitation-related extremes (maximum consecutive dry days, maximum consecutive 5-day precipitation and extremely wet days' total amount). Overall, results from this study indicate a very low sensitivity of projected changes in this region to model resolution. While fine resolution is critical for capturing the spatial variability of the control climate, it may not be as important for capturing the climate response to homogeneous forcing (in this case greenhouse gas concentration changes).
\end{abstract}

Keywords Climate change $\cdot$ Regional climate model $\cdot$ Horizontal resolution $\cdot$ China

\section{Introduction}

Coupled global atmosphere-ocean general circulation models (GCMs) are the primary tools used to investigate the response of the climate system to increases in greenhouse

Xuejie Gao

gaoxj@cma.gov.cn

1 National Climate Center, China Meteorological Administration, Beijing 100081, China

2 Department of Civil and Environmental Engineering and Center for Environmental Sciences and Engineering, University of Connecticut, Storrs, CT 06269, USA

3 Climate Change Research Center, Institute of Atmospheric Physics, Chinese Academy of Sciences, Beijing 100029, China

4 University of Chinese Academy of Sciences, Beijing 100049, China gas (GHG) concentrations and to conduct climate change projections. While the current generation of coupled global GCMs participating in Phase 5 of Coupled Model Intercomparison Project (CMIP5, Taylor et al. 2012) are of higher spatial resolution and more comprehensive than their precedents (CMIP3, Meehl et al. 2007), the resolution is still too coarse to capture the effects of local and regional forcing, especially in regions of strong surface heterogeneity. One such region is China, known for its complex topography especially over the Tibetan Plateau area (IPCC 2013). Climate in this region is strongly influenced by monsoon and land surface conditions. Coupled GCMs have difficulty in reproducing the regional climate especially the precipitation patterns here, for which coarse resolution was suggested as a main cause (e.g., Jiang et al. 2005; Xu et al. 2010; Yu et al. 2011). Compared to GCMs, nested high-resolution regional climate models (RCMs) were shown to greatly improve the representation of fine-scale forcing and land surface 
heterogeneity over China (e.g., Gao et al. 2001, 2006, 2013; Qian and Leung 2007; Zou and Zhou 2013).

Increasing resolution of RCMs has been found to improve the model performance in capturing both the spatial patterns and magnitudes of mean climate and climate extremes (e.g., Giorgi and Marinucci 1995; Leung and Qian 2003; Tang et al. 2007; Kendon et al. 2012; Giorgi et al. 2016; Gao et al. 2017). For example, Gao et al. (2006) conducted RCM experiments with the resolution change across the range of 60-360 km over East Asia, and the results show that the model resolutions of $60 \mathrm{~km}$ or higher are needed to accurately simulate the distribution of precipitation. This finding was further confirmed by a follow up study on the spatial variability of monsoon precipitation (Gao et al. 2008). They showed that more detailed description of geographic features in a RCM can lead to a better placement and more accurate magnitude of monsoon precipitation maximum, while coarse resolution models tend to place the monsoon precipitation maximum too far inland. The impact of spatial resolution change on model performance is also sensitive to the range of changes. Rojas (2006) documented that much smaller improvements on present-day climate were obtained when increasing resolution from 45 to $15 \mathrm{~km}$ than from 135 to $45 \mathrm{~km}$. This can also be found in Gao et al. (2006), when the RCM resolution changing from 60 to $45 \mathrm{~km}$, the spatial correlation coefficient between simulated and observed annual mean precipitation increases a little, only from close to $0.80-0.81$, while the value is about 0.2 when the resolution is $360 \mathrm{~km}$.

Fine resolution is desirable not only for improving the model simulation of present-day climate but also for supporting impact assessment studies. Climate impact assessment and the development of regional to local-scale adaptation strategies require climate change information be available at locally-relevant spatial scales. Therefore, with increasingly accessible computing resources, the horizontal resolution in RCM simulations becomes higher and higher, and some use a grid size of $10 \mathrm{~km}$ or less, especially over small domains of interest, e.g., over the Carpathian Basin (Torma et al. 2010), the United Kingdom (Kendon et al. 2012), the Tibetan Plateau (Ji and Kang 2013), and the Alpine chain (Giorgi et al. 2016). In most climate change projection studies using RCMs, due to its long time integration and high demand for computational resources, the resolution is mostly above $20 \mathrm{~km}$ and the model is often driven by boundary conditions from one global model (e.g., Giorgi et al. 2004; Im et al. 2008; Gao et al. 2012; Yu et al. 2015). Therefore, most studies focused on comparing the coarseresolution GCMs projections with the finer-resolution RCM projections (e.g., Deque et al. 2005; Coppola and Giorgi 2010; Gao et al. 2013). Few have compared RCM projections at different resolutions. Gao et al. (2012) conducted two RCM simulations with two different resolutions (20 vs.
$25 \mathrm{~km}$ ) over East Asia, and found that the two projected a similar pattern of future precipitation changes over western China but a contrasting pattern over eastern China. However, this finding is subject to a high degree of uncertainty, as the two projections differ not only in resolution but also in the driving GCMs, $\mathrm{CO}_{2}$ concentration scenarios, and the time duration. Similar problems also existed in the comparisons between the experiments with different resolutions over Europe (e.g., Coppola and Giorgi 2010; Jacob et al. 2014).

This study investigates the potential sensitivity of future projections to RCM model spatial resolution. Using a regional climate model (RegCM4.4) driven by initial and lateral boundary conditions derived from a CMIP5 global climate model, we conduct two sets of climate change experiments to illustrate whether and how the spatial resolution might influence a RCM's projection for future changes. Section 2 describes the model, data and experimental design. The model validation and analysis of future changes are discussed in Sect. 3 and 4, and the main conclusions and discussions are presented in Sect. 5.

\section{Model, experimental design and introduction of climate extreme indices}

The global climate model used here is HadGEM2-ES, which is from Met Office Hadley Centre (hereafter referred to as HadGEM). HadGEM is a coupled AOGCM with atmospheric resolution of $\mathrm{N} 96\left(1.875^{\circ} \times 1.25^{\circ}\right)$ with 38 vertical levels and an ocean resolution of $1^{\circ}$ (increasing to $1 / 3^{\circ}$ at the equator) and 40 vertical levels (Jones et al. 2011). Compared to the previous version, the primary new components added to the physical climate model in HadGEM are the terrestrial and ocean ecosystems and gas-phase tropospheric chemistry, along with their coupled interactions (Collins et al. 2011), and was used for the core climate simulations for CMIP5.

A recent version of the Abdus Salam International Center for Theoretical Physics (ICTP) Regional Climate Model, RegCM4.4 (Giorgi et al. 2012) is employed in this study. The model is run at its default configuration of 18 vertical sigma layers with two different horizontal resolutions, 50 and $25 \mathrm{~km}$ (hereafter referred to as HdR_50km and HdR_25km, respectively). Based on the performance of different convective schemes in RegCM4.4 experiments over China (Gao et al. 2016), here we choose the land surface scheme CLM3.5 (Oleson et al. 2008) and the convection scheme of Emanuel (Emanuel 1991). Other model physics include computations employing the non-local formulation of Holtslag et al. (1990) for planetary boundary layer, resolvable scale precipitation scheme of Pal et al. (2000), and the atmospheric radiative transfer scheme from the NCAR community climate model CCM3 (Kiehl et al. 1998). 
Note that the default land cover data used in the RegCM4.4 and CLM3.5 shows large discrepancies compared to reality over China. Thus, as reported by Han et al. (2015), the land cover data was updated based on the vegetation map of China and the surface emissivity for bare soil and snow were changed from 0.96 to 0.97 to 0.80 and 0.92 , respectively.

The model domain in this study is the same as the Phase II East Asia domain of the international COordinated Regional climate Downscaling EXperiment (CORDEX, Giorgi et al. 2009), which encompasses the whole continental China and adjacent areas. The topographical fields of HadGEM, HdR_50km and HdR_25km are presented in Fig. 1b-d, respectively. Better definition of topography and coastlines in HdR_25km compared to the driving GCM and lower resolution of RCM is evident from these figures. The HdR _25km simulation is a consecutive one with a total of 140 years. It covers the period of 1961-2005 for the present day (with observed GHG concentrations) and 2006-2099 for the future with GHG concentrations following the RCP4.5 and RCP8.5 scenarios (taken from the RCP scenarios data group (http://www.pik-potsdam.de/ mmalte/rcps/), Moss et al. 2010). But for the HdR_50km simulation, two time periods of 1985-2005 and 2079-2099 under both scenarios are conducted, the first year for each time slice is considered as spin-up and not included in the analysis.

The evaluation of model performance makes use of three standard metrics, the bias, the spatial correlation coefficient (COR) and the root-mean-square error (RMSE). Observation data is from CN05.1, developed by $\mathrm{Wu}$ and Gao (2013), which is an augmentation of CN05 (Xu et al. 2009). Different spatial resolutions of $0.25^{\circ}, 0.5^{\circ}$ and $1^{\circ}$ are available in CN05.1. Since the models do not use the same horizontal grid, when comparing the HadGEM, HdR_50km and HdR_25km simulations, we need to interpolate all the original data onto the same grid spacing. Here three different resolutions (corresponding to the resolution of the observational data, $0.25^{\circ}, 0.5^{\circ}$, and $1.0^{\circ}$ ) have been tested, and the results show little difference. For convenience, we present most of the comparison at the $1^{\circ}$ resolution. The results analysis are based on the end of the century (2080-2099) under RCP8.5 relative to the "present day" period of 1986-2005 (a) Topography, GTOPO30, m

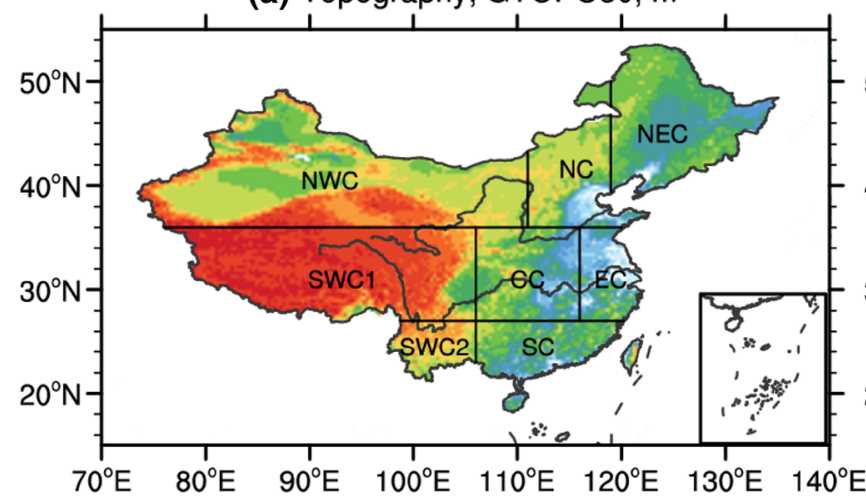

(c) Topography, HdR_50km, m

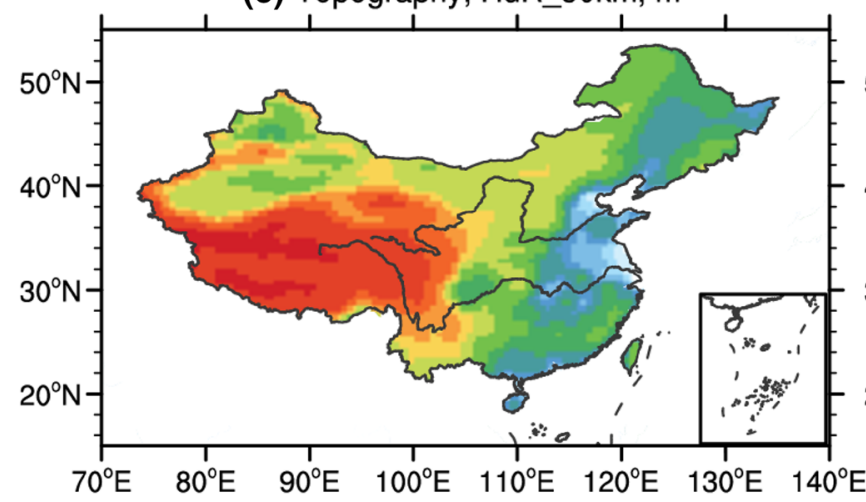

(b) Topography, HadGEM, m

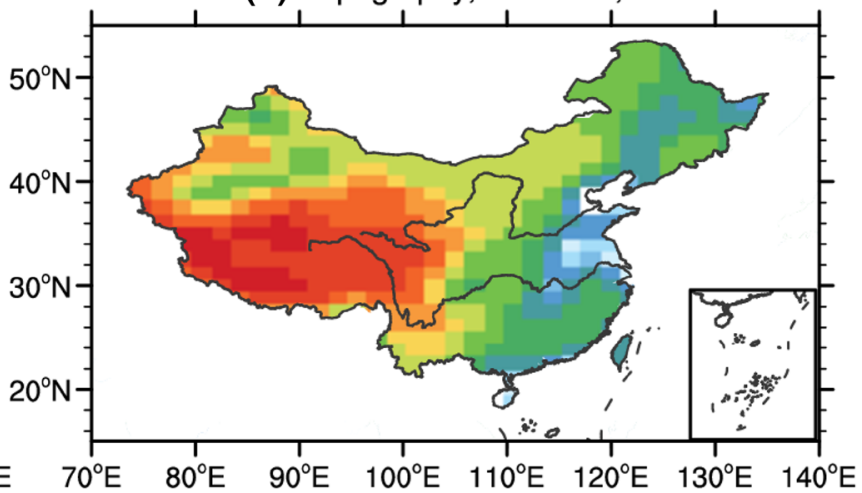

(d) Topography, HdR_25km, m

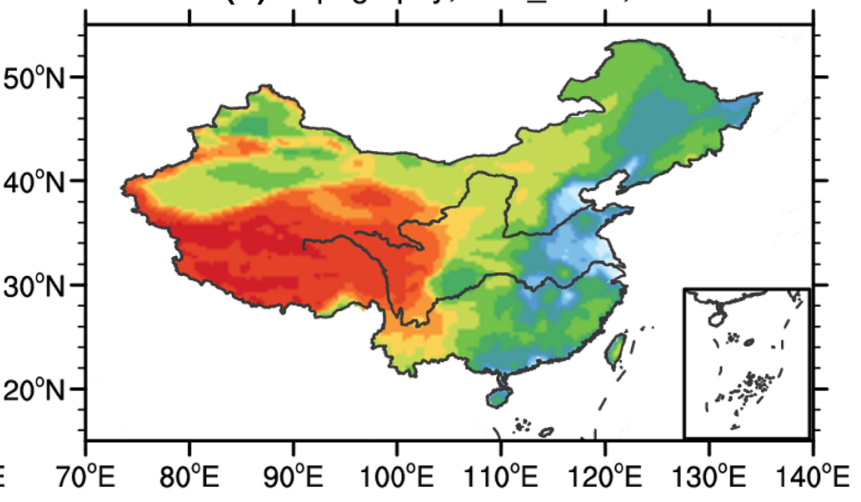

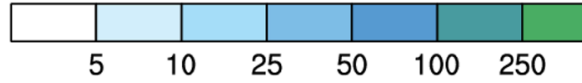

$\begin{array}{lllllll}500 & 1000 & 1500 & 2000 & 3000 & 4000 & 5000\end{array}$

Fig. 1 Topography over China (land only, unit m) (a Observation; b HadGEM; c HdR_50km; d HdR_25km). 8 sub-regions are selected for present study: Northeast China (NEC), North China (NC), East
China (EC), Central China (CC), South China (SC), Southwest China region 1 (SWC1), Southwest China region 2 (SWC2), and Northwest China (NWC) 
to focus on the high end of the range of future changes in our simulations.

Six indices of climate extremes following the definition of the expert team on climate change detection and indices (ETCCDI) (Karl et al. 1999; Frich et al. 2002; Zhang et al. 2011) are selected to illustrate the model performance in simulating the climate extremes. These include three temperature-related indices of summer days (SU), the warmest day (TXx), the coldest night (TNn), and the other three precipitation-related indices of the maximum number of consecutive dry days (CDD), the maximum consecutive 5-day precipitation (RX5day) and extremely wet days' total amount (R95P). Detailed definitions of the indices are listed in Table 1.

\section{Validation of the climate model}

\subsection{Temperature}

Figure 2 shows the observed mean temperature and model bias (model minus observation) simulated by HadGEM, HdR _50km and HdR_25km in DJF and JJA over China for the period of 1986 to 2005. In DJF, distinct latitudinal distribution of the observed temperature is found in eastern China, with temperature over $12{ }^{\circ} \mathrm{C}$ in southern China and below $-18{ }^{\circ} \mathrm{C}$ in the Northeast (Fig. 2a). In western China, topography is the primary controlling factor, with temperature below $-9{ }^{\circ} \mathrm{C}$ over the mountains in the Northwest and Tibetan Plateau but close to zero in the Tarim Basin. The HadGEM model underestimates temperature in general, with a greater cold bias of $-5{ }^{\circ} \mathrm{C}$ or more over the western part of China (Fig. 2b). Different from the global model, the HdR_50km simulation produced dominantly warm biases over most areas of Northwest, Northeast and South China. The magnitude of the biases are mainly in the range of $-2.5-2.5{ }^{\circ} \mathrm{C}$ with an exception over the Tibetan Plateau where large cold bias $\left(-5\right.$ to $-2.5^{\circ} \mathrm{C}$ ) are found (Fig. 2c). The spatial distribution and magnitude of temperature biases in HdR_25km simulation are similar to those in HdR_50km, but with a greater cold bias over the Tibetan Plateau and a smaller warm bias over South China (Fig. 2d).
Relative to the DJF season, temperature in JJA shows a much lower degree of spatial heterogeneity and a much smaller latitudinal gradient in eastern China. High temperature in the range of $27-30{ }^{\circ} \mathrm{C}$ can be found in the basins of Northwest China, the mid and lower reaches of the Yangtze River, and South China along the southern coast (Fig. 2e). The model biases in JJA are generally smaller than in DJF in all of the three simulations. HadGEM produced warm and cold biases in northern and southern China, respectively, with larger cold biases in the basins of the Northwest (Fig. 2f). HdR_50km produced biases within $\pm 1{ }^{\circ} \mathrm{C}$ over most areas of East China, and warm biases in the range of $2.5-5{ }^{\circ} \mathrm{C}$ in the Northwest (Fig. $2 \mathrm{~g}$ ). Results from HdR_25km are similar to HdR_50km, with slightly larger magnitude of warm and cold biases (Fig. $2 \mathrm{~h}$ ).

For a more quantitative evaluation, the relative frequency and Taylor diagram are selected to illustrate the difference among the simulations. Firstly, we divided China into eight sub-regions following Xu et al. (2015), namely, Northeast China (NEC), North China (NC), East China (EC), Central China (CC), South China (SC), Southwest China region 1 (SWC1), Southwest China region 2 (SWC2), and Northwest China (NWC), as shown in Fig. 1a. Relative frequency distributions of temperature biases in China and its eight subregions in DJF and JJA are shown in Fig. 3. As shown in the figure, biases in HadGEM during DJF are dominantly cold in all the sub-regions and China, with only a few grid points showing a warm bias. Compared to the global model, HdR_50km and HdR_25km perform much better, with most of the biases in the range of -5 to $5{ }^{\circ} \mathrm{C}$. Specifically, in the HdR_25km simulation, the mode of biases is around $0{ }^{\circ} \mathrm{C}$ in NEC, NC, EC, CC, SC, SWC1, and warm biases are dominant in NWC and whole China. In HdR_50km, the results are similar to HdR_25km in most sub-regions except for SC and SWC1 where warm biases are more spatially extensive than in HdR_25km (Fig. 3a, c, e, g, i, k, m, o, q). In JJA, HadGEM produced dominantly warm biases in NEC, NC, SWC2 and China, which contradict those in DJF; for other sub-regions, the mode of the biases is around $0{ }^{\circ} \mathrm{C}$. For both HdR_50km and HdR_25km, the distribution of biases is more symmetric in most sub-regions and whole China, and the magnitude of biases is smaller than in the global model
Table 1 Definitions of selected six climate extreme temperature and precipitation indices

\begin{tabular}{lll}
\hline Indices & Definition & Unit \\
\hline SU & Annual total number of daily maximum temperature $>25{ }^{\circ} \mathrm{C}$ & days \\
TXx & Maximum value of daily maximum temperature & ${ }^{\circ} \mathrm{C}$ \\
TNn & Minimum value of daily minimum temperature & ${ }^{\circ} \mathrm{C}$ \\
CDD & Maximum number of consecutive dry days (daily precipitation amount $(R$ day $)<1 \mathrm{~mm})$ & days \\
RX5day & Maximum consecutive 5-day precipitation & $\mathrm{mm}$ \\
R95P & Annual total precipitation due to events exceeding the 95 th percentile of all wet days $(R$ & $\mathrm{mm}$ \\
& day $\geq 1 \mathrm{~mm})$ of a given climate reference period & \\
\hline
\end{tabular}


(a) Mean tmp. in DJF, $1986-2005, \mathrm{CN} 05.1,{ }^{\circ} \mathrm{C}$

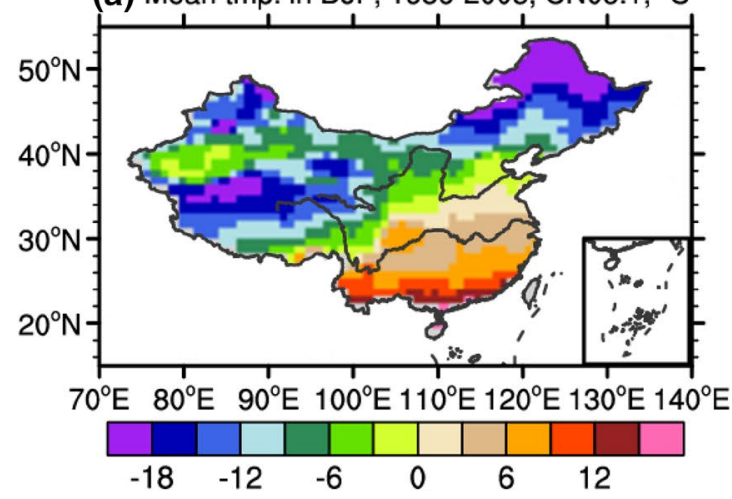

(b) Tmp. diff., DJF, 1986-2005, HadGEM, ${ }^{\circ} \mathrm{C}$

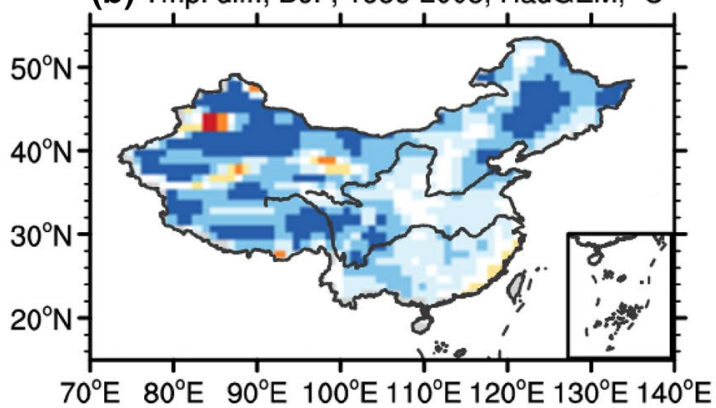

(c) Tmp. diff., DJF, 1986-2005, HdR_50km, ${ }^{\circ} \mathrm{C}$

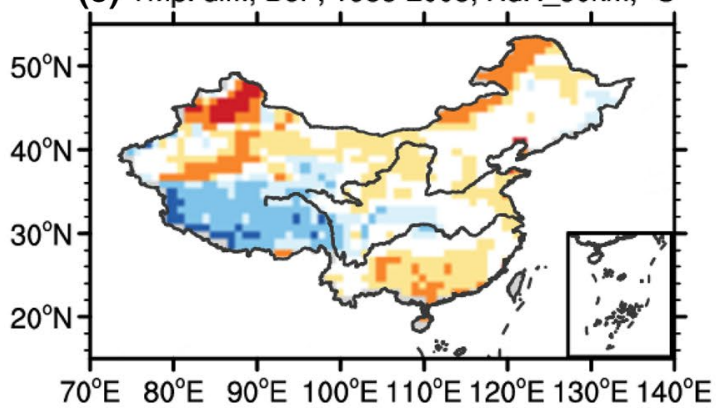

(d) Tmp. diff., DJF, 1986-2005, HdR_25km, ${ }^{\circ} \mathrm{C}$

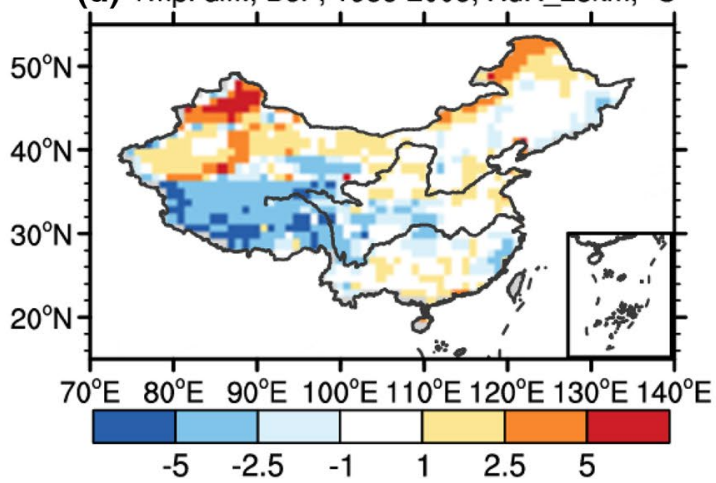

(e) Mean tmp. in JJA, 1986-2005, CN05.1, ${ }^{\circ} \mathrm{C}$

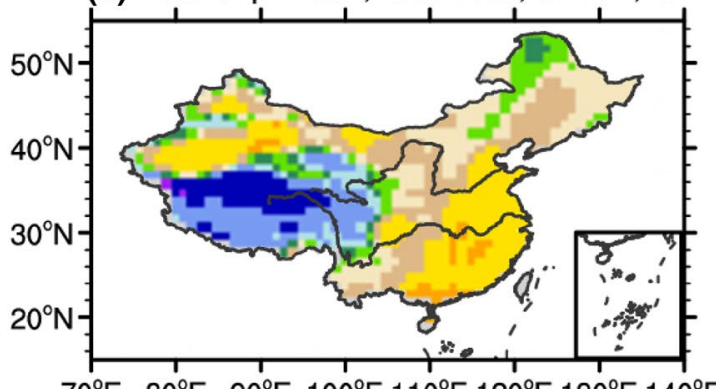

$70^{\circ} \mathrm{E} \quad 80^{\circ} \mathrm{E} \quad 90^{\circ} \mathrm{E} \quad 100^{\circ} \mathrm{E} 110^{\circ} \mathrm{E} 120^{\circ} \mathrm{E} 130^{\circ} \mathrm{E} 140^{\circ} \mathrm{E}$

$\begin{array}{lllllllllll}3 & 6 & 9 & 12 & 15 & 18 & 21 & 24 & 27 & 30 & 33\end{array}$

(f) Tmp. diff., JJA, 1986-2005, HadGEM, ${ }^{\circ} \mathrm{C}$

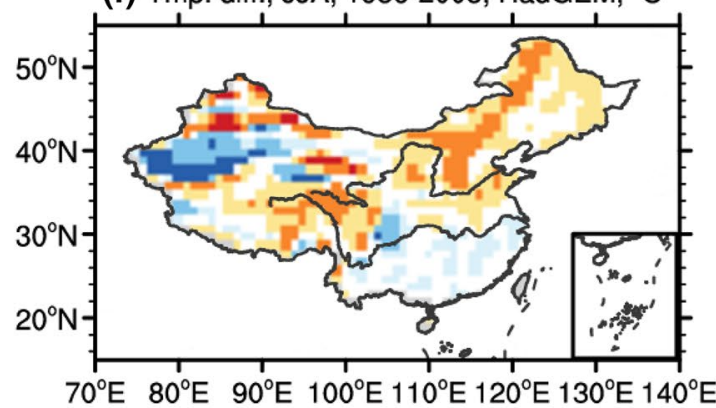

(g) Tmp. diff., JJA, 1986-2005, HdR_50km, ${ }^{\circ} \mathrm{C}$

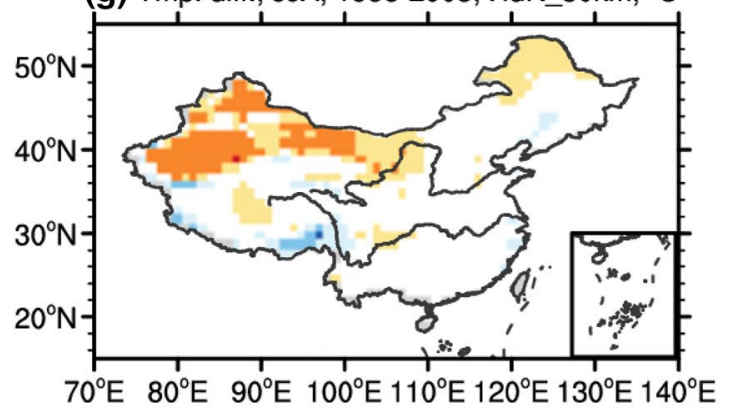

(h) Tmp. diff., JJA, 1986-2005, HdR_25km, ${ }^{\circ} \mathrm{C}$

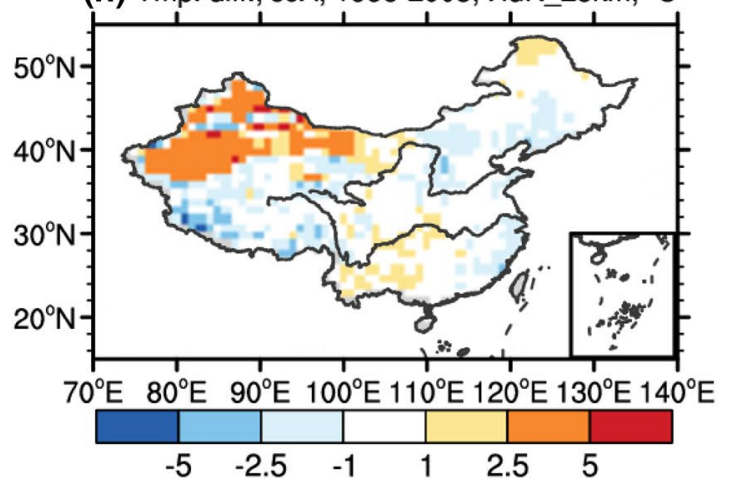

Fig. 2 The observed mean temperature in DJF (a) and JJA (e) of 1986-2005 over China, and the model bias in HadGEM (b, f), HdR_50km (c, g) and HdR_25km $(\mathbf{d}, \mathbf{h})$ simulations (unit, $\left.{ }^{\circ} \mathrm{C}\right)$

(Fig. 3b, d, f, h, j, l, n, p, r). Furthermore, there is not much difference in EC, CC, SC, and SWC1 between the two RCM simulations, while in the other regions, a left-ward shift can be found in HdR_25km compared to HdR_50km. 

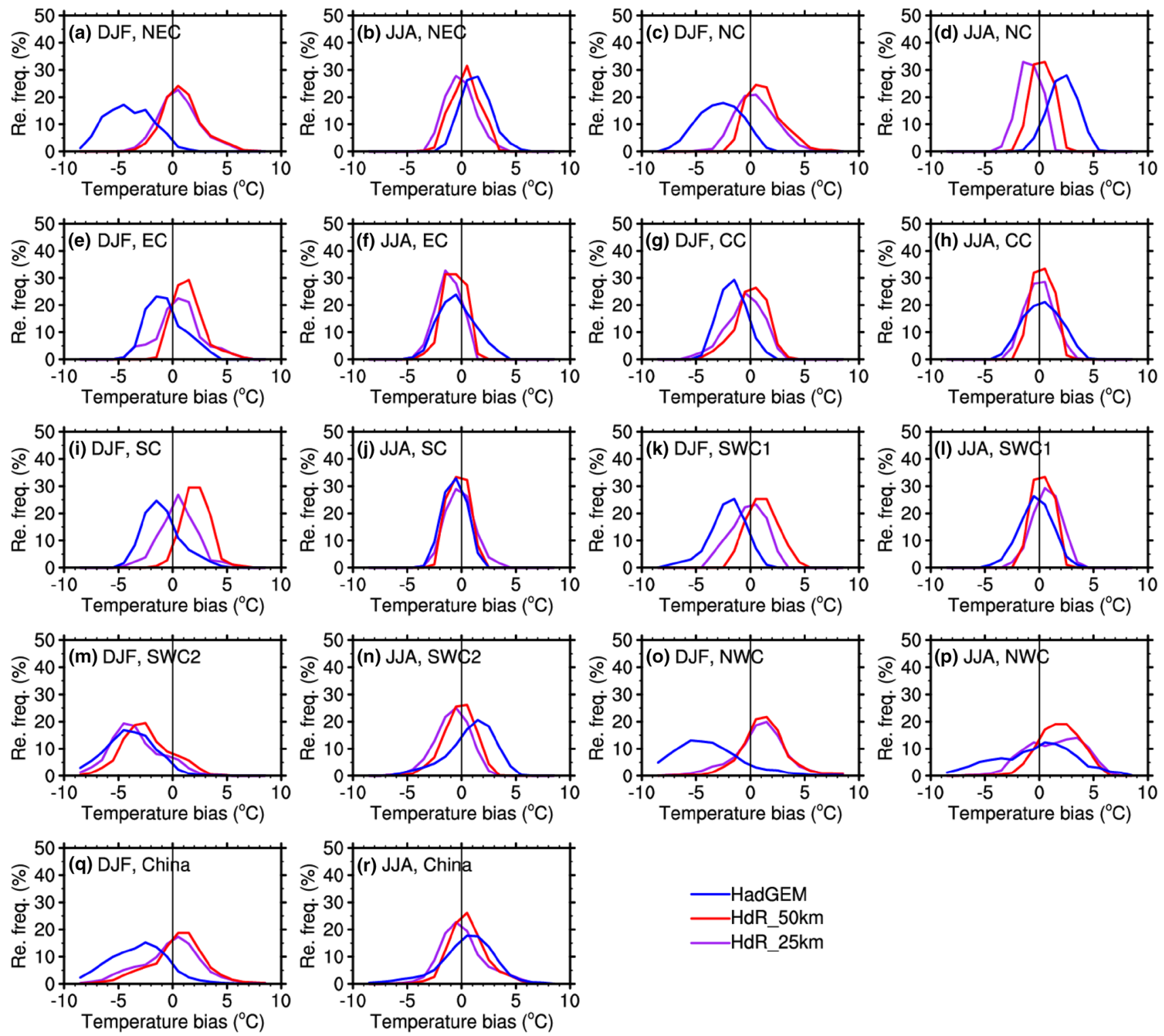

Fig. 3 Relative frequency (\%) of temperature bias in DJF (1st and 3rd column) and JJA (2nd and 4th column) over China and its eight subregions derived from the HadGEM (blue line), HdR_50km (red line)

Taylor diagram is a concise statistical summary of how well different patterns match each other in terms of COR, RMSE, and ratio of variances (Taylor 2001). Figure 4a, c present the Taylor diagrams of mean temperature for DJF and JJA. All three simulations well reproduce temperature with high CORs. In DJF, the CORs for most sub-regions are above 0.80, except NWC (0.63) in HadGEM and EC $(0.59)$ in HdR_25km. The normalized RMSEs of the simulations relative to the observation are mainly in the range of $0.25-0.75$, and the ratios of variances of the simulations to the observation are mainly around 1 . Similar results of high CORs, low RMSEs, and ratios around 1 can also be found in JJA, except the EC in HadGEM.

and HdR_25km (purple line) simulations (land only, unit, ${ }^{\circ} \mathrm{C}$ ). Bin size for temperature (deltaT) is $1^{\circ}$

Overall, these results indicate a clearly better performance of the RCMs than the global model, and increasing the spatial resolution from 50 to $25 \mathrm{~km}$ does not seem to enhance the regional model performance much.

\subsection{Precipitation}

The observed and simulated mean precipitation in DJF and JJA is presented in Fig. 5. Observational data shows less than $0.25 \mathrm{~mm} /$ day precipitation over most areas in the north, greater than $1.5 \mathrm{~mm} /$ day south of the Yangtze River, and a maxima exceeding $2.5 \mathrm{~mm} /$ day in the southeast (Fig. 5a). The model simulations in general capture the observed 
(a) Temp., DJF

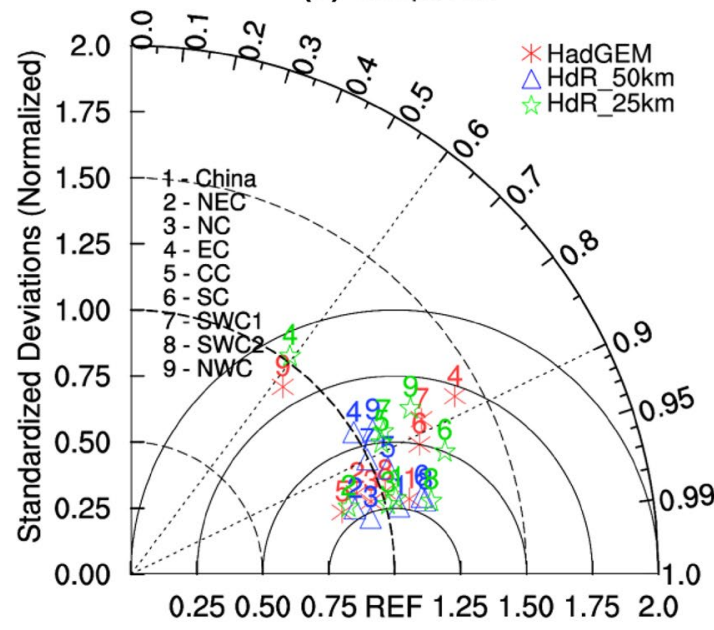

(c) Temp., JJA

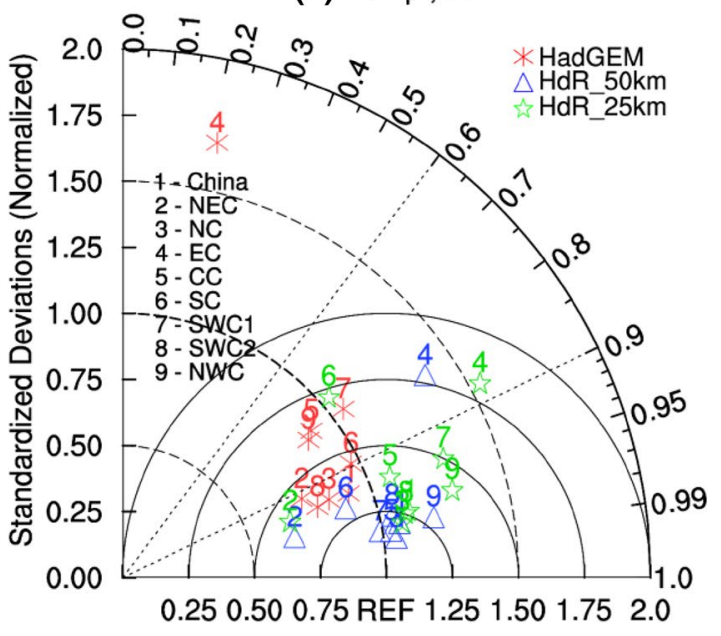

(b) Pre., DJF

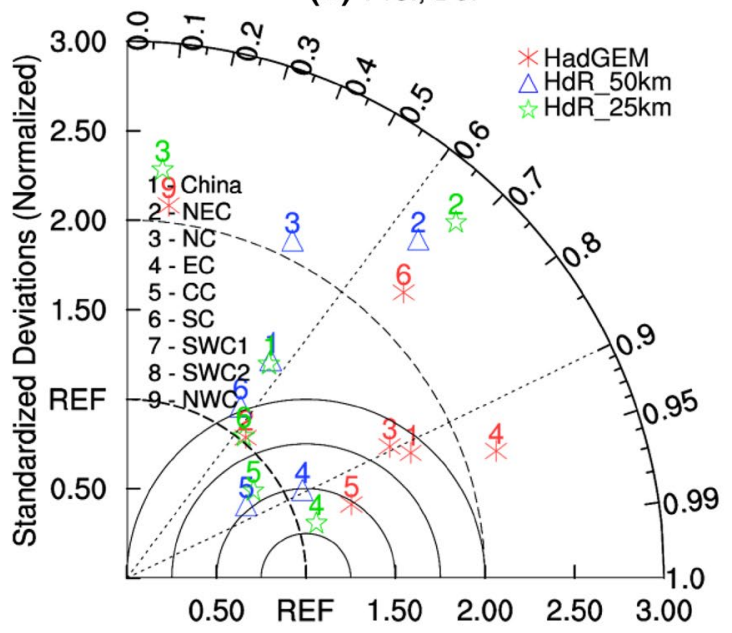

(d) Pre., JJA

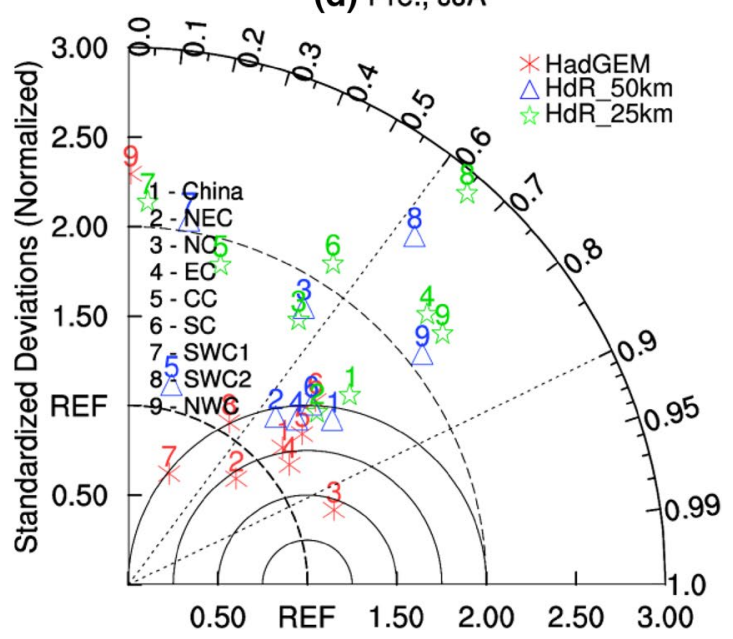

Fig. 4 Taylor diagram for temperature (a, c) and precipitation $(\mathbf{b}, \mathbf{d})$ in DJF (top row) and JJA (bottom row)

spatial pattern with an increasing gradient from the northwest to southeast (Fig. 5b-d). In HadGEM, a dominant wet bias can be found in most of the domain. Compared to HadGEM, the magnitude of the wet biases in HdR_50km simulation is larger, especially over Northeast China; some underestimation can be found in South China. Both the pattern and magnitude of biases are similar between the HdR_25km and HdR_50km simulations. The model's relatively poor performance over Northwest China, especially in the mountains there may be related to the uncertainties in the observation datasets (Wu et al. 2011).

Located in the East Asian monsoon region, summer is the rainy season for China. Precipitation greater than $5 \mathrm{~mm} /$ day can be found in the south in JJA, and decreases towards the north and northwest (Fig. 5e-h). This spatial pattern is in general well captured by the models and there is little difference between the models with three different resolutions (figures not shown). Specifically, in HadGEM, an overestimation and a mixture of over- and under- estimation can be found over West and East China, respectively. In addition, the biases are larger over the west than the east (Fig. 5f). Similar to the DJF season, both the spatial pattern and magnitude of precipitation in HdR_50km and HdR_25km are similar, with a dry bias in Northwest China and mostly wet bias over other regions. Compared between the two RCM simulations, the bias over the northwestern part of China is more significant in HdR_50km simulation (Fig. 5g, h).

The relative frequency distributions of precipitation bias in DJF and JJA are shown in Fig. 6. Due to the very low precipitation in DJF, the value at the zero point of the $\mathrm{x}$ axis in whole China, which is $30.2,29.7$, and $28.4 \%$ for HadGEM, HdR_50km and HdR_25km, respectively, is the percentage of the number of points with bias between 0.25 and $0.75 \mathrm{~mm} /$ day. The second highest percentage can be found in the range of -0.25 to $0.25 \mathrm{~mm} /$ day $(27.9 .0,26.4$ and 
(a) Pre., DJF, 1986-2005, CN05.1, mm/d

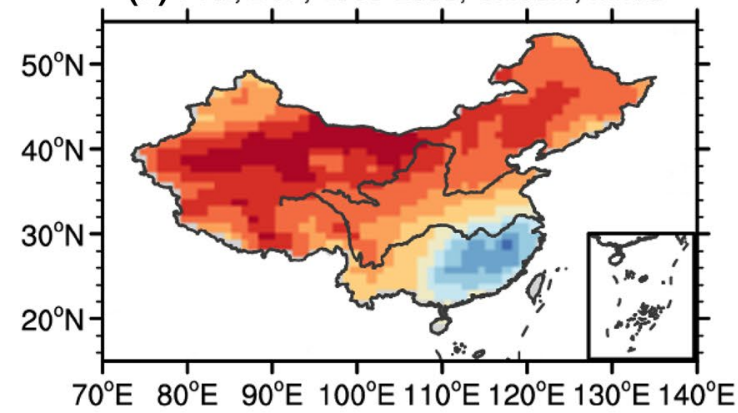

(b) Pre., DJF, 1986-2005, HadGEM, mm/d

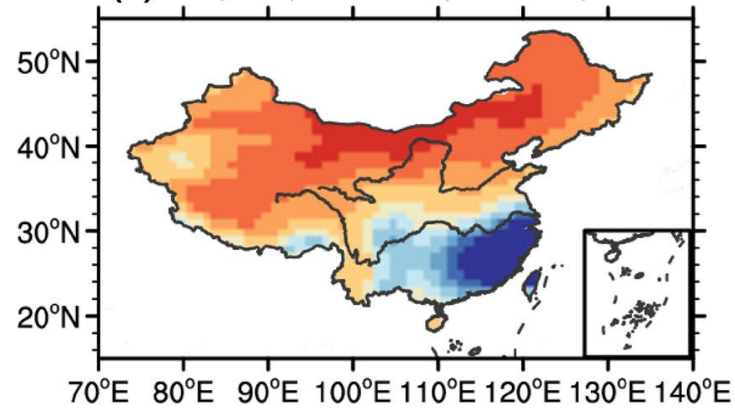

(c) Pre., DJF, 1986-2005, HdR_50km, mm/d

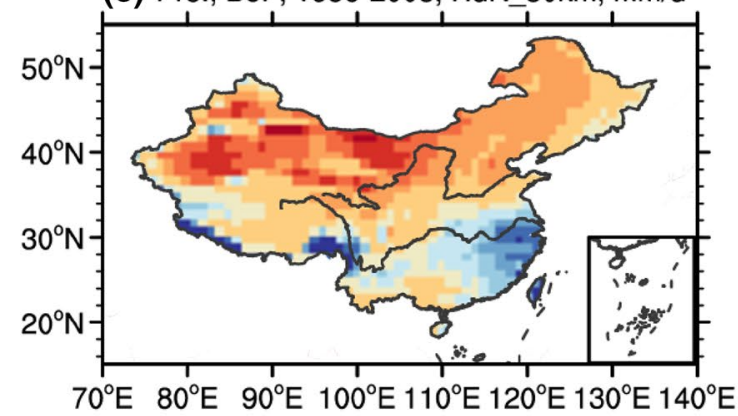

(d) Pre., DJF, 1986-2005, HdR_25km, mm/d

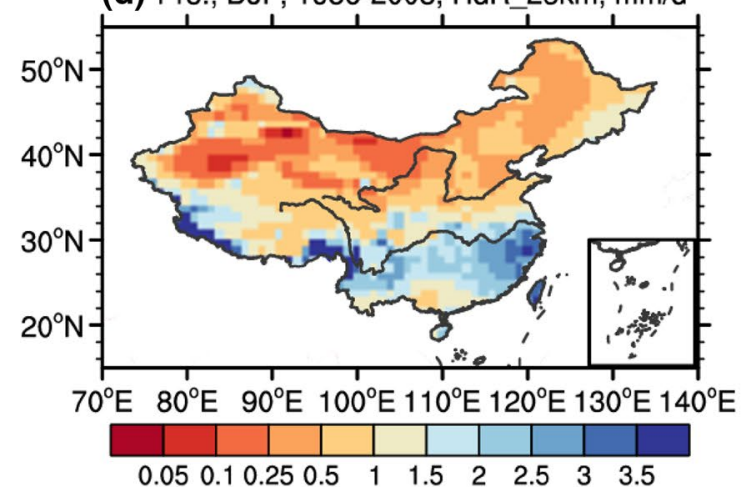

(e) Mean pre. in JJA, 1986-2005, CN05.1, mm/d

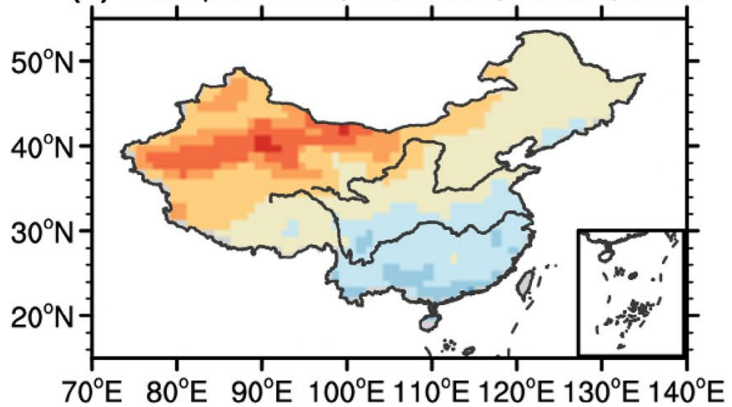

(f) Pre., JJA, 1986-2005, HadGEM, mm/d

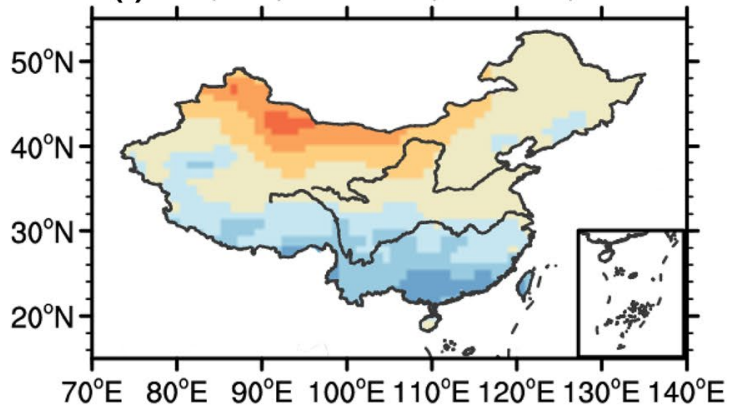

(g) Pre., JJA, 1986-2005, HdR_50km, mm/d

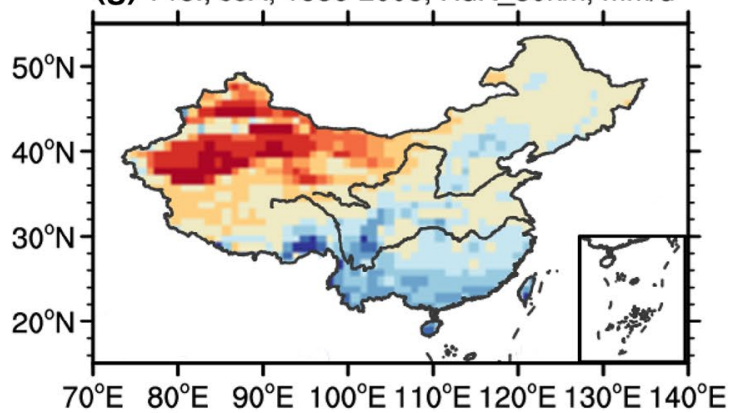

(h) Pre., JJA, 1986-2005, HdR_25km, mm/d

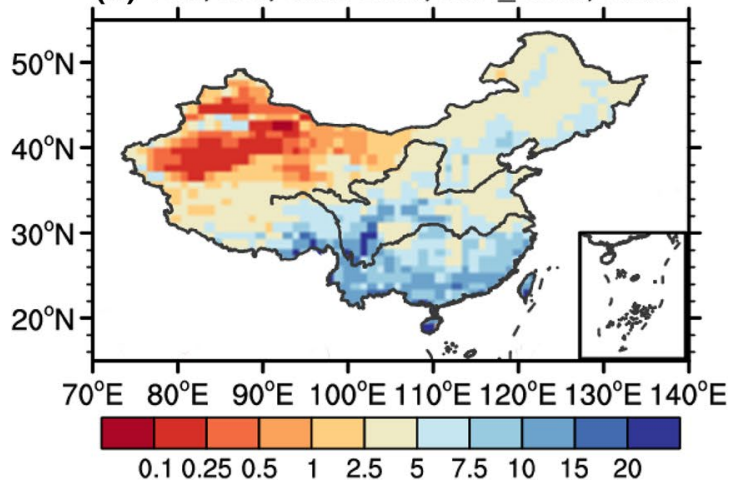

Fig. 5 The observed and simulated mean precipitation in DJF (a-d) and JJA (e-h) of 1986-2005 over China (land only, unit: mm/day). (a, e CN05.1; b, f HadGEM; c, g HdR_50km; d, h HdR_25km)

24.5\%) (Fig. 6q). Of the eight sub-regions, wet biases are dominant in EC, CC, SWC1, SWC2, and NWC in all three models. Wet biases are also significant in SC for HadGEM, and in NEC and NC for the two RCM simulations. Some difference in SC can be found, with wet biases in HadGEM and dry biases in the two RCMs. In JJA, the mode of the biases is around $0 \mathrm{~mm} /$ day for NEC, NWC, and whole China in all three simulations; wet biases are dominant in $\mathrm{NC}, \mathrm{SC}$, 

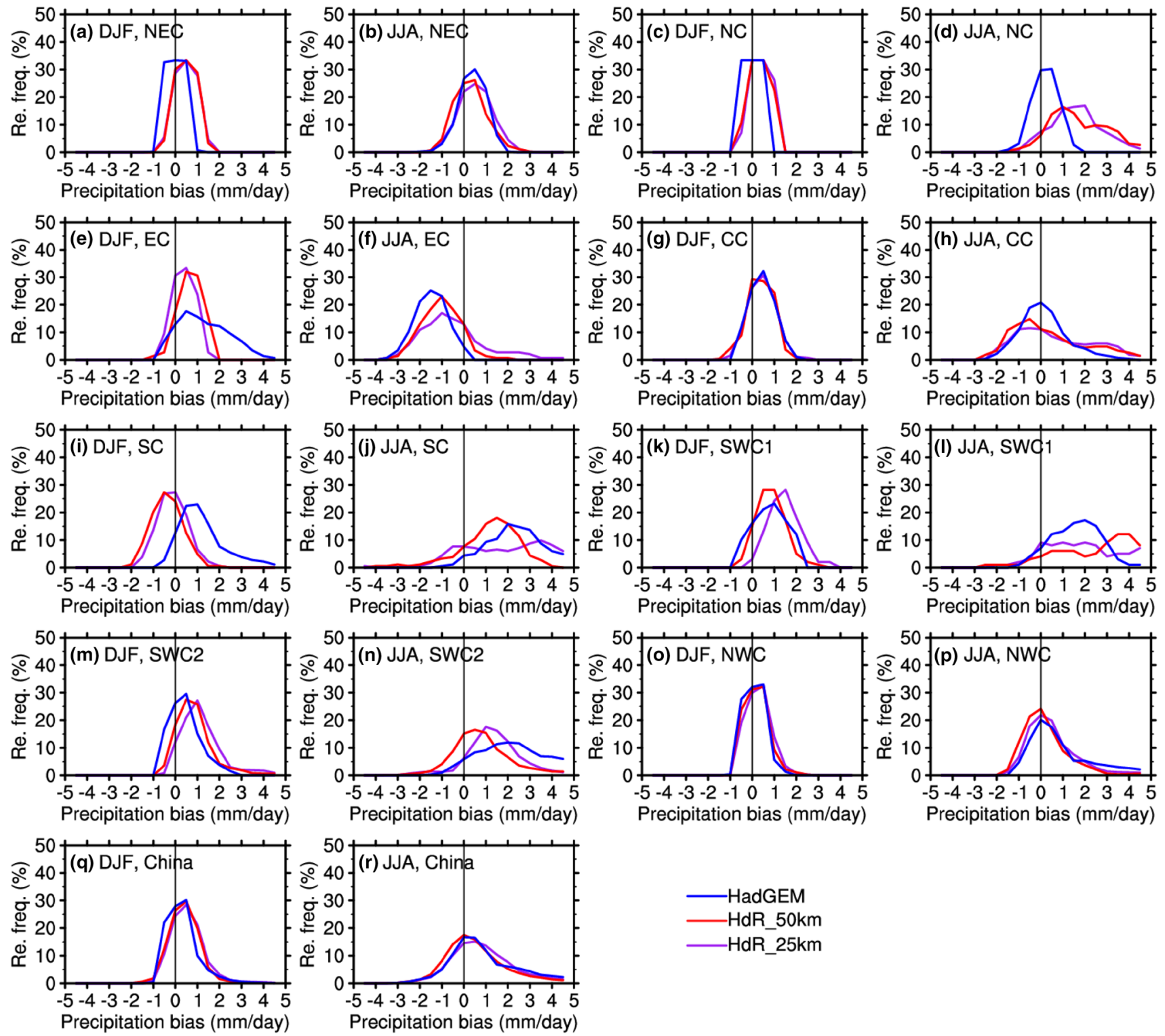

Fig. 6 Similar to Fig. 3, but for precipitation bias (unit $\mathrm{mm} /$ day). Bin size for precipitation (deltaP) is $0.5 \mathrm{~mm} /$ day

SWC1, and SWC2; dry biases are dominant in EC and CC. Compared among the three models, the relative frequency distributions are very similar in most sub-regions except $\mathrm{NC}$ in which HadGEM performs better.

Taylor diagrams of mean precipitation in DJF and JJA are shown in Fig. 4b, d. Compared with that of temperature, the inter-region spread for precipitation is much larger and the CORs are remarkably lower. In DJF, the CORs are from below 0.1 to above 0.9 and the ratios of variances of the simulations to the observation are from 0.5 to 3.0. Compared to DJF, less inter-region spread can be found in JJA with the CORs mostly in the range of 0.6-0.9 and the models of HadGEM and HdR $50 \mathrm{~km}$ are closer to the reference point. For the whole China, the CORs between the model simulations and observation are $0.92,0.53,0.54$ in DJF and $0.75,0.80,0.75$ in JJA, for HadGEM, HdR_50km, and HdR_25km, respectively. Overall, results from the two RCM simulations show no clear advantage over the GCM runs in capturing the mean climatology of the precipitation.

\subsection{Climate extremes}

\subsubsection{Temperature extreme indices}

Figure 7 presents the temperature-related climate extremes. Two observed maximum center of SU can be found in northwestern basins and South China, with the value greater than 150 days (Fig. 7a). Due to the cold bias in temperature 
(a) SU, CN05.1, 1986-2005, days

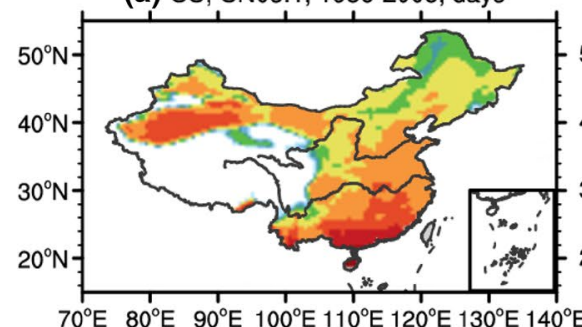

(b) SU, HadGEM, 1986-2005, days

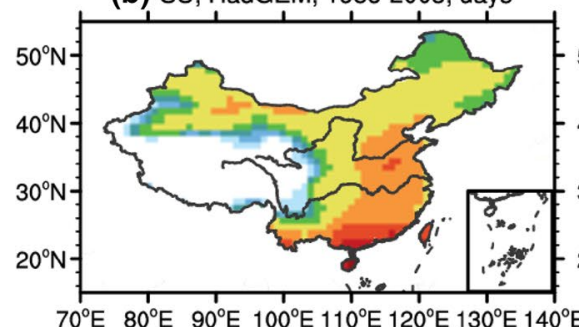

(c) SU, HdR_50km, 1986-2005, days

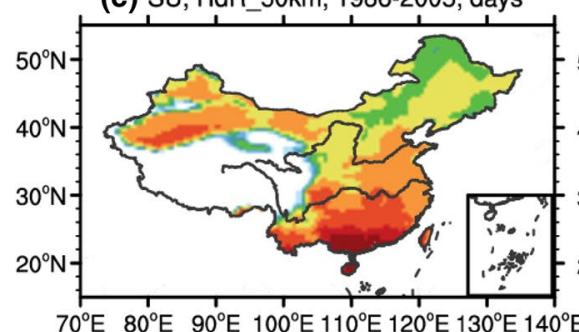

(d) SU, HdR_25km, 1986-2005, days

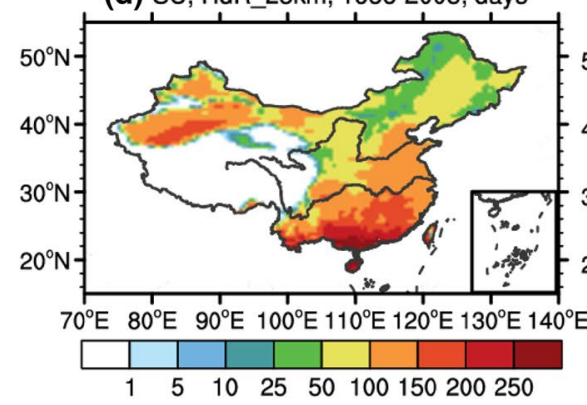

(e) TXx, CN05.1, 1986-2005, ${ }^{\circ} \mathrm{C}$

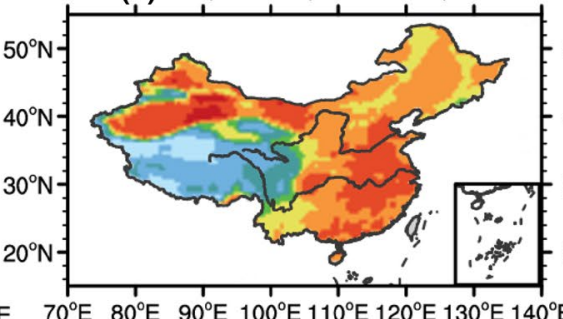

(f) TXX, HadGEM, $1986-2005,{ }^{\circ} \mathrm{C}$

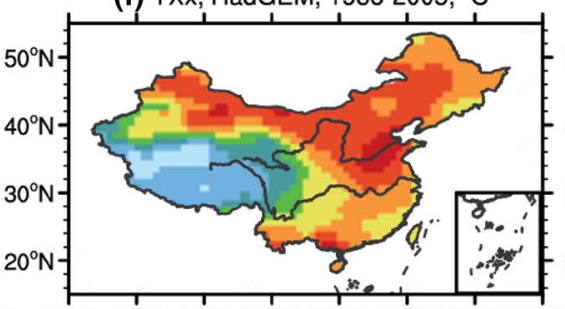

(g) TXx, HdR_50km, $1986-2005,{ }^{\circ} \mathrm{C}$

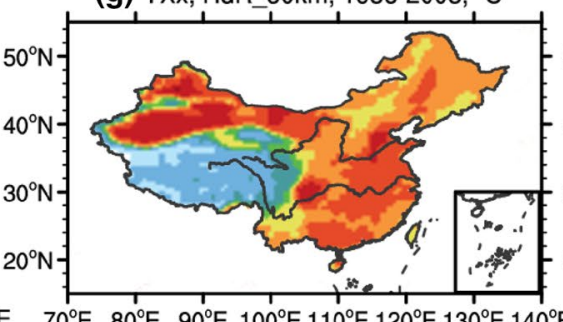

(h) TXx, HdR_25km, 1986-2005, ${ }^{\circ} \mathrm{C}$

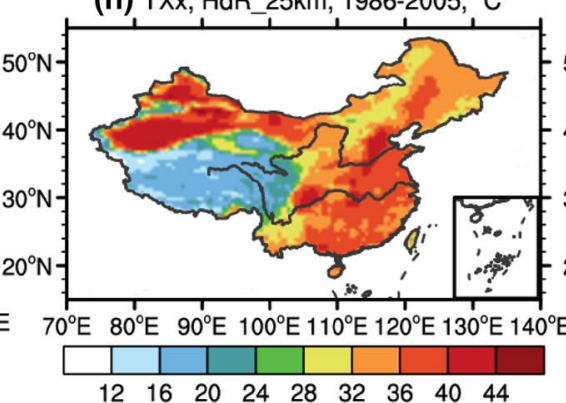

(i) TNn, CN05.1, 1986-2005, ${ }^{\circ} \mathrm{C}$

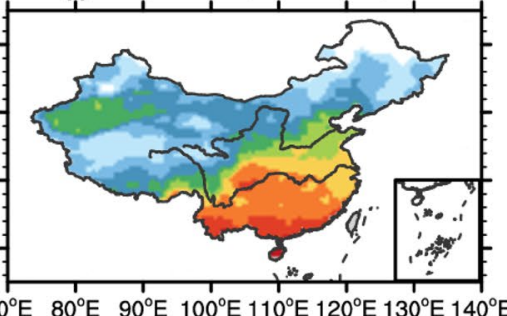

(j) TNn, HadGEM, $1986-2005,{ }^{\circ} \mathrm{C}$

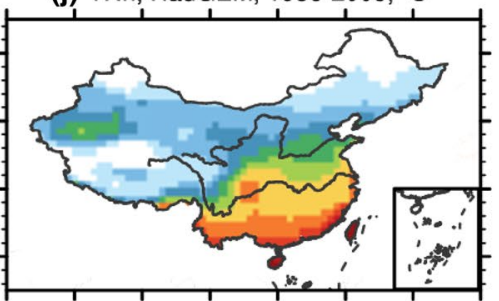

(k) TNn, HdR_50km, $1986-2005,{ }^{\circ} \mathrm{C}$

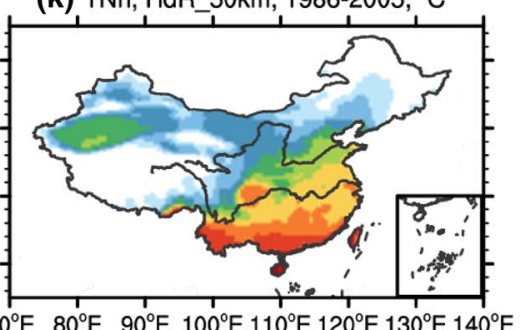

(I) TNn, HdR_25km, 1986-2005, ${ }^{\circ} \mathrm{C}$

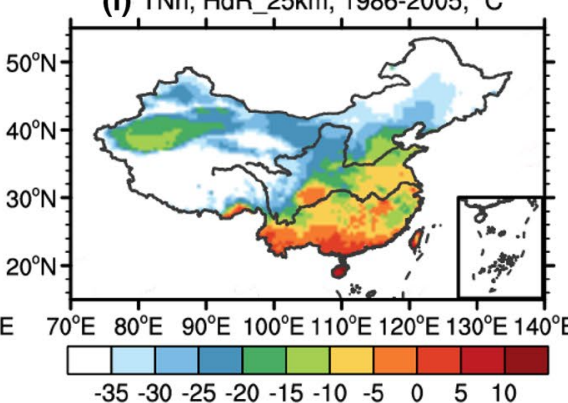

Fig. 7 The observed and simulated mean temperature-related climate extremes of SU (a-d, days), TXx $\left(\mathbf{e}-\mathbf{h}\right.$, $\left.{ }^{\circ} \mathrm{C}\right)$ and $\mathrm{TNn}\left(\mathbf{i}-\mathbf{l},{ }^{\circ} \mathrm{C}\right)$ in $1986-$ 2005 over China based on observation data (top row), HadGEM (2nd row), HdR_50km (3rd row) and HdR_25km (bottom row)

simulation, the value of SU in HadGEM simulation is much lower than observations, especially over the northwestern part of China (Fig. 7b). However, both RCM simulations capture the pattern and magnitude of SU well, including the high values over the Qaidam Basin and low values over its surrounding areas (Fig. 7c, d). The CORs are 0.85, 0.97, 0.97 and RMSEs are 38, 17, 16 days for HadGEM, HdR_50km and HdR_25km, respectively (Table 2).

Larger TXx of over $36{ }^{\circ} \mathrm{C}$ are observed in Northwest China, from the lower reach of the Yellow River to the lower reach of the Yangtze River, the Sichuan Basin and along the southeast coast (Fig. 7e). The models well reproduce the spatial distribution in general, especially for the two RCMs.
In the HadGEM simulation, the high values are centered on the broad areas of North China, and lower than observation values can be found in Northwest China. The RCM simulations are greatly improved both in the spatial pattern and magnitude in addition to providing more spatial details (Fig. $7 \mathrm{f}-\mathrm{h}$ ). The spatial correlation coefficient is $0.86,0.98$, and 0.98 for HadGEM, HdR_50km and HdR_25km, respectively (Table 2).

The observed pattern of TNn is similar to that of the mean temperature in DJF, which shows a primarily latitudinal gradient in East China and a strong dependence on topography in West China. But greater gradient from below $-35{ }^{\circ} \mathrm{C}$ in the north to over $5{ }^{\circ} \mathrm{C}$ in the south than that in 
Table 2 Spatial correlation coefficients (CORs) and RMSEs of temperature- and precipitation-related climate extremes, between each of the HadGEM, HdR_50km, HdR_25km simulations and observation

\begin{tabular}{|c|c|c|c|c|c|c|}
\hline & \multicolumn{3}{|l|}{ COR } & \multicolumn{3}{|l|}{ RMSE } \\
\hline & HadGEM & HdR_50km & HdR_25km & HadGEM & HdR_50km & HdR_25km \\
\hline SU (days) & 0.85 & 0.97 & 0.97 & 38 & 17 & 16 \\
\hline $\operatorname{TXx}\left({ }^{\circ} \mathrm{C}\right)$ & 0.86 & 0.98 & 0.98 & 4 & 2 & 2 \\
\hline $\mathrm{TNn}\left({ }^{\circ} \mathrm{C}\right)$ & 0.96 & 0.94 & 0.92 & 5 & 6 & 7 \\
\hline CDD (days) & 0.58 & 0.49 & 0.50 & 49 & 61 & 67 \\
\hline RX5day (mm) & 0.89 & 0.73 & 0.78 & 36 & 56 & 50 \\
\hline R95p (mm) & 0.88 & 0.66 & 0.75 & 95 & 156 & 150 \\
\hline
\end{tabular}

mean temperature in DJF can be found (Fig. 7i). The models reproduce the pattern well, with a spatial correlation coefficient of 0.96, 0.94, and 0.92 for HadGEM, HdR_50km and HdR_25km, respectively (Table 2). Compared to HadGEM, a stronger cold bias over the Tibetan Plateau and Northeast China can be found in the two RCM simulations (Fig. 7j-1).

\subsubsection{Precipitation extreme indices}

The precipitation-related extremes are provided in Fig. 8. As an indicator of drought, CDD of more than 150 days are observed over arid and semi-arid region in northwestern China, while it is mostly less than 50 days in South China (Fig. 8a). HadGEM overestimates CDD over Inner Mongolia and underestimates over most of the western China (Fig. 8b). Both RCMs overestimate CDD over north of Northwest China and underestimate over other areas in the north (Fig. 8c, d), and differences between the two RCMs are small. Biases in all three simulations in South China are within \pm 10 days. The CORs are $0.58,0.49,0.50$ and RMSEs are 49, 61, 67 days for HadGEM, HdR_50km and HdR_25km, respectively (Table 2). Note that the maxima bias in the west may relate to the observation datasets as the sparse meteorological station data there and indeed the results including other two precipitation-related indices from TRMM data with high resolution shows much difference from the observed data we used in this paper (figures not shown).

Observed RX5day shows a decreasing gradient from the southeast to northwest, consistent with the precipitation pattern in DJF and JJA (Fig. 8e). Both the GCM and the two RCM simulations capture this reasonably well, with a relatively high correlation coefficient of $0.89,0.73$ and 0.78 . However, dominantly wet biases are found in the three simulations, with stronger biases over the West and South China in HadGEM simulation and from northeast to southwest in the two RCM simulations (Fig. 8f-h). In addition, the two RCM simulations share similar spatial pattern and magnitudes. The RMSEs for the three models are 36, 56 and $50 \mathrm{~mm}$, respectively (Table 2 ).

The spatial distribution of observed R95P is similar to that of mean precipitation, with more rain falling in extremes in the south and less in the west (Fig. 8i). In the simulations, the wet bias over Northwest China also remains there like the mean precipitation, although there is some difference among them. In HadGEM simulation, the maxima value of bias is located in the basins of western China and South China, while it is mainly over the southwestern China in the two RCM simulations (Fig. 8j-1). The CORs is 0.88 , 0.66 and 0.75 for HadGEM, HdR_50km and HdR_25km, respectively, and the corresponding RMSEs are 95, 156 and $150 \mathrm{~mm}$ (Table 2).

\subsection{Daily precipitation intensity}

From the validation of the present-day climate, different resolutions' simulations by regional climate model generally show similar broad patterns both in mean climate and climate extremes; however, at the higher-resolution experiments, finer detail is present, especially in areas of complex topography and coastlines, such as the Qaidam basin and Qilian Mountain. The added value of high-resolution regional climate modeling has been documented recently in a number of studies in reproducing different characteristics of precipitation and precipitation-related extremes forced by topography (Giorgi et al. 2014, 2016; Torma et al. 2015). Results show that the outputs from the GCMs are close to the coarse resolution observational data while the nested RCMs are close to the high one. In order to further investigate the added value in the RCMs, the probability density function (PDF) of daily precipitation intensity distribution in whole China and its eight sub-regions in the present day climate from observations and simulations are analyzed (Fig. 9). In addition to the CN05.1 data at $1^{\circ}$ resolution, three observational datasets at different resolutions have been added to account for the observational data uncertainty, including the NMIC data of Shen and Xiong (2015) with a grid spacing of $0.25^{\circ} \times 0.25^{\circ}$, the Xie et al. (2007) data at $0.5^{\circ} \times 0.5^{\circ}$, and GPCP data of Huffman et al. (2001) at $1.0^{\circ} \times 1.0^{\circ}$.

In all regions, a difference between the fine and coarse scale PDFs, both in the observation and simulation datasets can be found. For example, in NEC, the observed CN05.1, GPCP and HadGEM simulated data produce events that at most reach about $150 \mathrm{~mm} /$ day and the PDF of HadGEM 
(a) CDD, CN05.1, 1986-2005, days

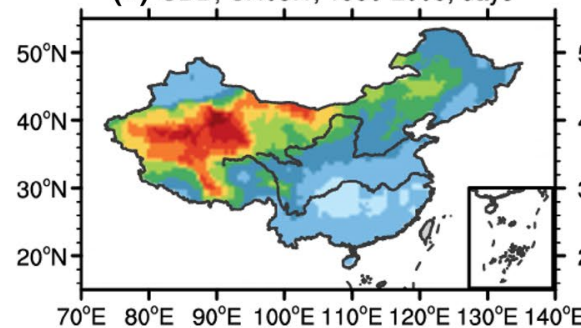

(b) CDD, HadGEM, 1986-2005, days

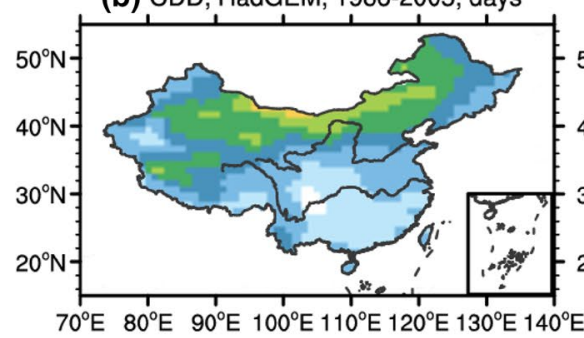

(c) CDD, HdR_50km, 1986-2005, days

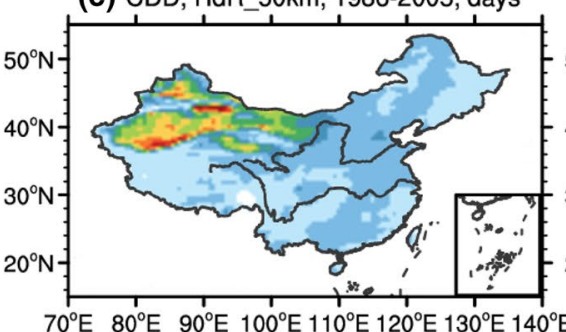

(d) CDD, HdR_25km, 1986-2005, days

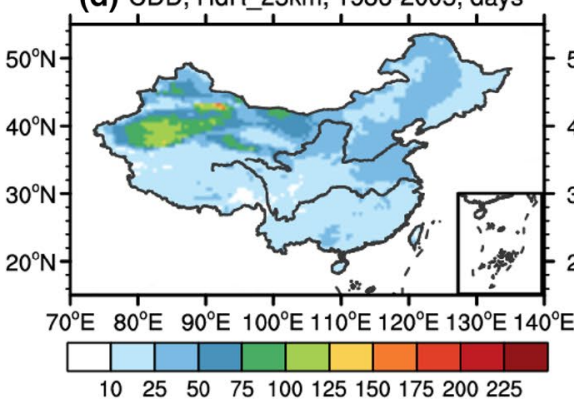

(e) RX5day, CN05.1, 1986-2005, mm

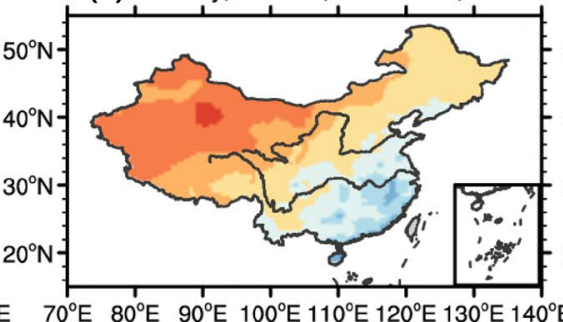

(f) RX5day, HadGEM, 1986-2005, mm

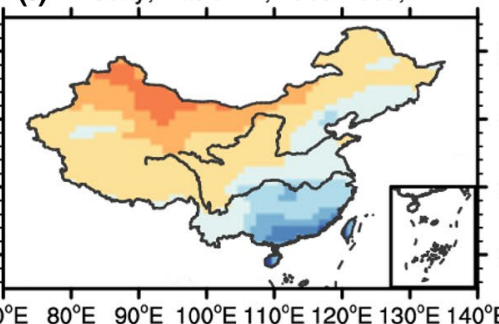

(g) RX5day, HdR_50km, 1986-2005, mm

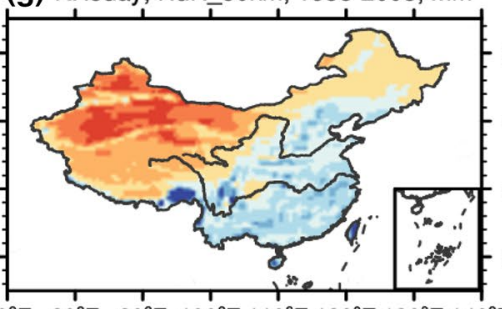

(h) RX5day, HdR 25km, 1986-2005, mm

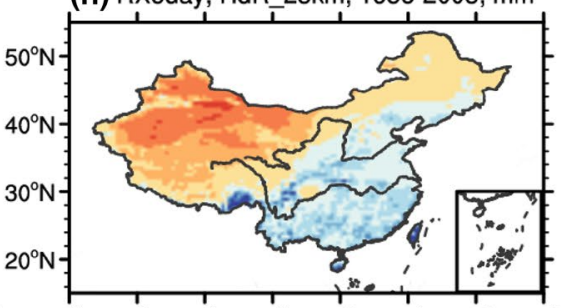

$70^{\circ} \mathrm{E} \quad 80^{\circ} \mathrm{E} \quad 90^{\circ} \mathrm{E} 100^{\circ} \mathrm{E} 110^{\circ} \mathrm{E} 120^{\circ} \mathrm{E} 130^{\circ} \mathrm{E} 140^{\circ} \mathrm{E}$

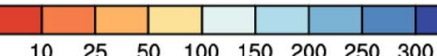

(i) R95P, CN05.1, 1986-2005, mm

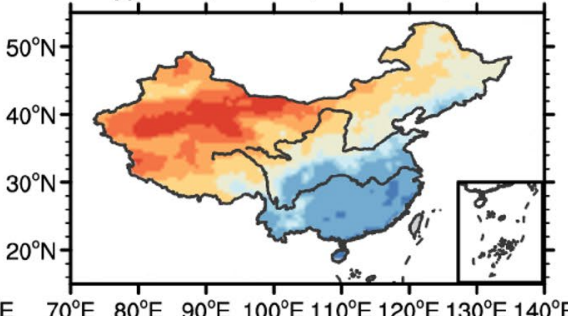

(j) R95P, HadGEM, 1986-2005, mm

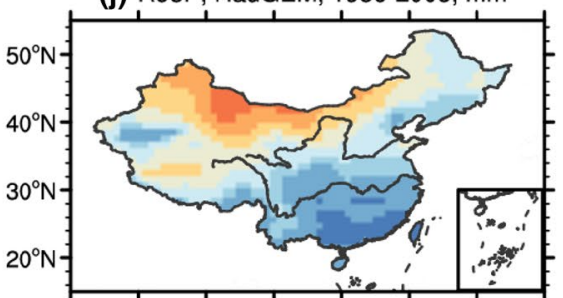

$70^{\circ} \mathrm{E} \quad 80^{\circ} \mathrm{E} \quad 90^{\circ} \mathrm{E} 100^{\circ} \mathrm{E} 110^{\circ} \mathrm{E} 120^{\circ} \mathrm{E} 130^{\circ} \mathrm{E} 140^{\circ} \mathrm{E}$

(k) R95P, HdR_50km, 1986-2005, mm

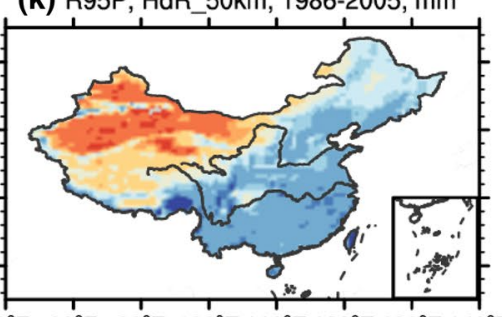

(I) R95P, HdR_25km, 1986-2005, mm

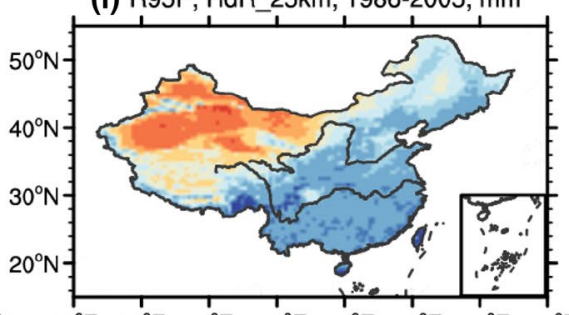

$70^{\circ} \mathrm{E} \quad 80^{\circ} \mathrm{E} \quad 90^{\circ} \mathrm{E} 100^{\circ} \mathrm{E} 110^{\circ} \mathrm{E} 120^{\circ} \mathrm{E} 130^{\circ} \mathrm{E} 140^{\circ} \mathrm{E}$

$\begin{array}{lllllllll}10 & 25 & 50 & 100 & 150 & 200250 & 500750\end{array}$

Fig. 8 Similar to Fig. 7, but for precipitation-related climate extremes of CDD (a-d, days), RX5day (e-h, mm) and R95p (i-1, mm)

is very similar to that of observation with coarse resolution. The Xie, NMIC, HdR_50km and HdR_25km produce a much longer tail with the maximum value larger than $250 \mathrm{~mm} / \mathrm{day}$, although the models overestimate the frequency of the events in the middle and end of the distribution. Similar results can also be found in NC, SWC1, EC, $\mathrm{CC}$ and SC; in NWC, SWC2 and whole China, the RCMs underestimate the frequency of the middle and heavy events and overestimate the light ones, while the HadGEM shows similar biases of the frequency in SWC2 and whole China but little difference can be found in NWC. In general, the HadGEM simulation is close to CN05.1 and GPCP, and the HdR_50km and HdR_25km simulations are close to Xie and
NMIC, which is in line with previous studies (Giorgi et al. 2014; Torma et al. 2015).

\section{Future changes}

\subsection{Temperature}

The projected temperature changes in winter (DJF) and summer (JJA) under the RCP8.5 scenario at the end of twenty-first century simulated by HadGEM, HdR_50km and HdR_25km are presented in Fig. 10. Generally, in all of the three simulations, larger temperature increase in the high 

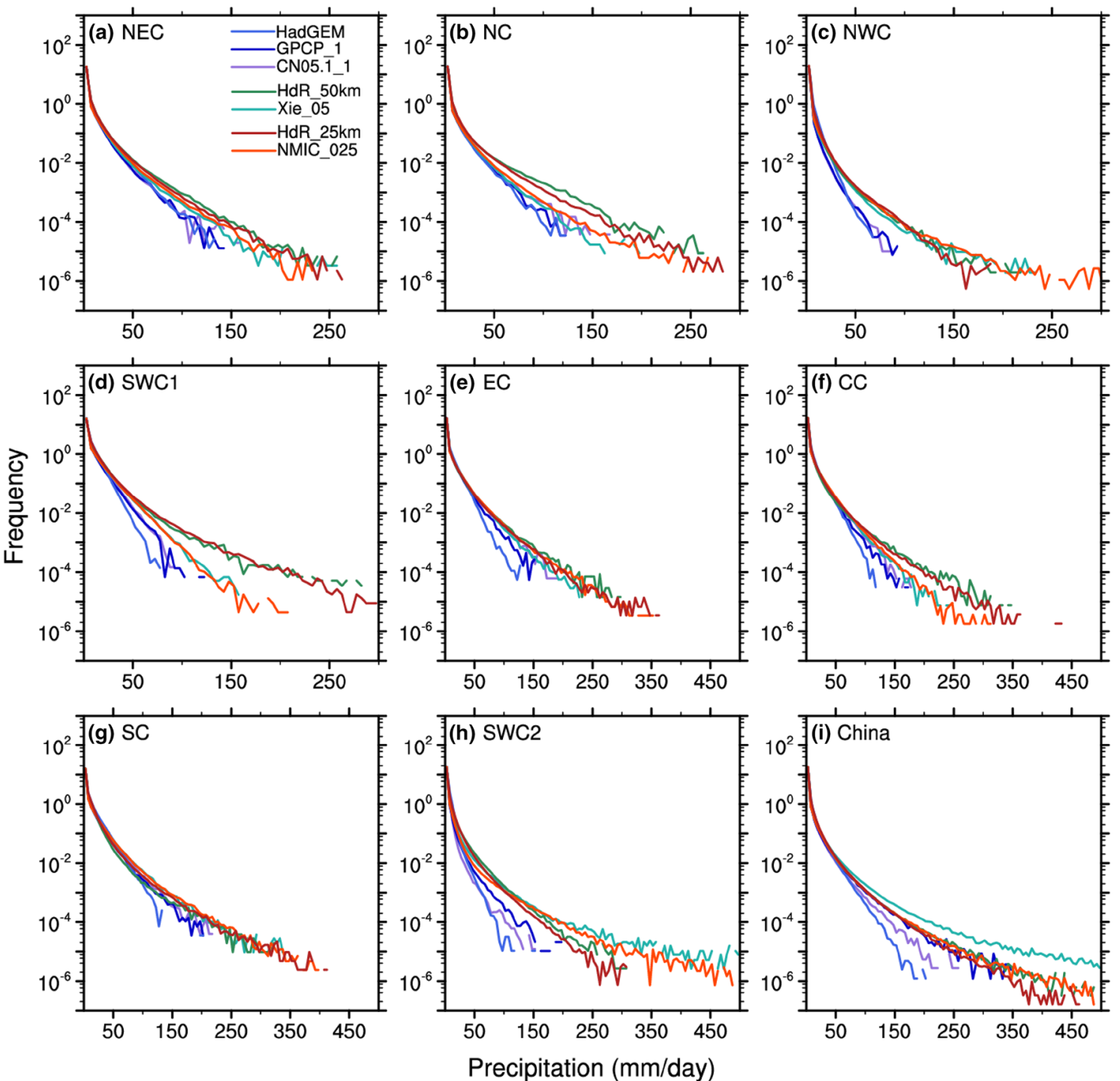

Fig. 9 Probability density function distributions of daily precipitation intensity ( $\mathrm{mm} /$ day) in whole China and its eight sub-regions derived from the observation datasets (CN05.1/GPCP/Xie/NMIC), HadGEM, HdR_50km and HdR_25km simulations

latitude (Northwest and Northeast China) and high elevation areas (Tibetan Plateau and the mountains) can be found in DJF compared to other parts of China. While in JJA, greater warming (exceeding $6.5^{\circ} \mathrm{C}$ ) are mainly in the northern part (the western regions of Inner Mongolia and Northwest China). Specifically, in HadGEM, greater increase of more than $8{ }^{\circ} \mathrm{C}$ in winter can be found in Northwest and Northeast China, while in summer, larger warming above $7{ }^{\circ} \mathrm{C}$ are presented in the basins of Northwest China and the lower reaches of the Yangtze River (Fig. 10a, b). The pattern and magnitude of changes are similar between the two RCM simulations, with greatest warming over the Tibetan Plateau in winter and in the northwestern part in summer. Compared to HadGEM, in the two RCMs, less warming in most areas of the domain can be found in both winter and summer except over the Tibetan Plateau (Fig. 10c-f).

The patterns of the changes under the RCP4.5 scenario are similar to RCP8.5 but are smaller in magnitude (figures not shown). Greater warming under RCP8.5 can also be found in the regional mean changes of the temperature in whole China and its sub-regions (Fig. 11). For example, relative to the present-day climate (1986-2005), the regional mean changes of the DJF temperature in whole China at the end of the century are $4.0,3.2,3.5{ }^{\circ} \mathrm{C}$ in HadGEM, HdR $\_50 \mathrm{~km}$ and HdR_25km, respectively, and are 7.0, 5.8, $5.8{ }^{\circ} \mathrm{C}$ for the RCP8.5 scenario simulations (Fig. 11c). In addition, warming in HadGEM model is more significant than the two RCMs in most sub-regions (more than six of them in both annual mean, DJF and JJA), especially under 
(a) Change of tmp., DJF, RCP85, HadGEM, ${ }^{\circ} \mathrm{C}$

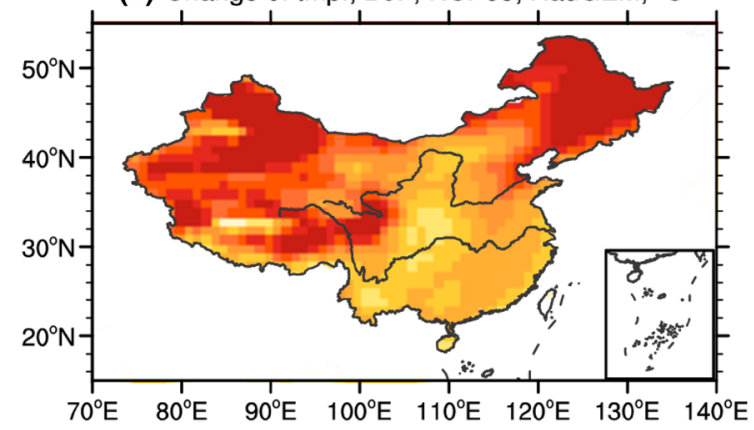

(c) Change of tmp., DJF, RCP85, HdR_50km, ${ }^{\circ} \mathrm{C}$

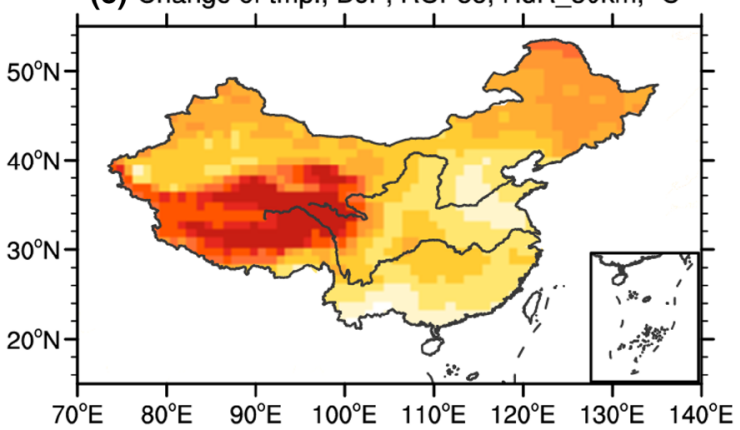

(e) Change of tmp., DJF, RCP85, HdR $25 \mathrm{~km},{ }^{\circ} \mathrm{C}$

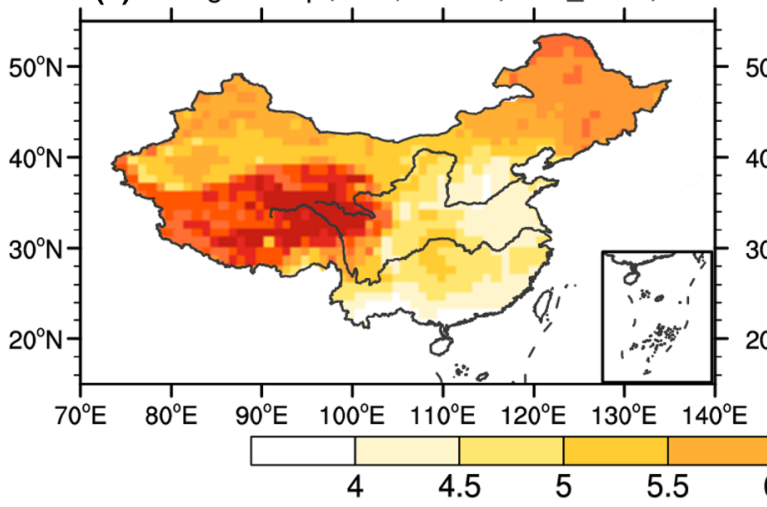

(b) Change of tmp., JJA, RCP85, HadGEM, ${ }^{\circ} \mathrm{C}$

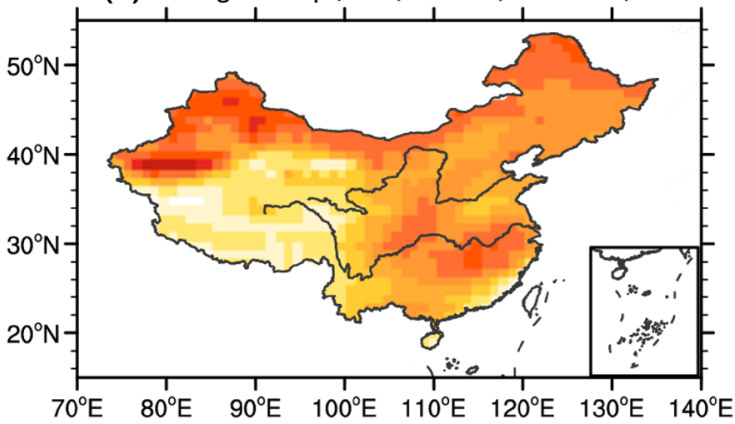

(d) Change of tmp., JJA, RCP85, HdR_50km, ${ }^{\circ} \mathrm{C}$

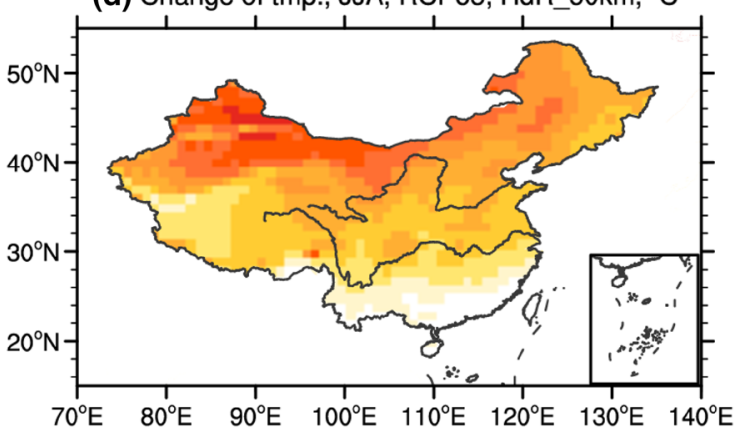

(f) Change of tmp., JJA, RCP85, $\mathrm{HdR} 25 \mathrm{~km},{ }^{\circ} \mathrm{C}$

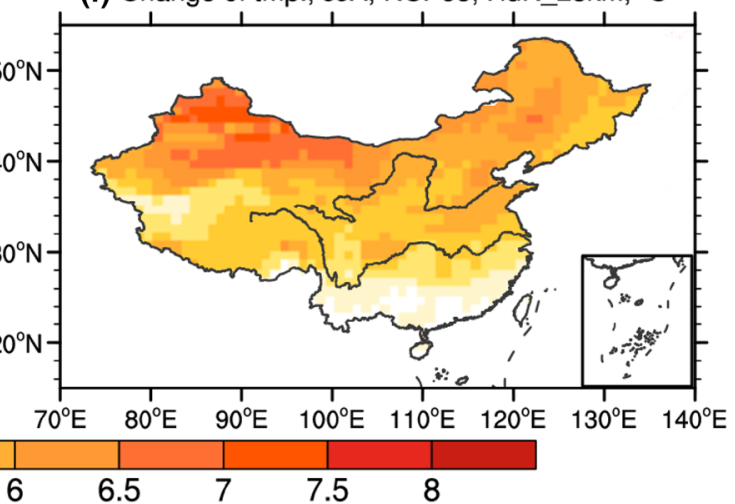

Fig. 10 Future changes of temperature in DJF (a, c, e) and JJA (b, d, f) at the end of twenty-first century under RCP8.5 scenario (unit $\left.{ }^{\circ} \mathrm{C}\right)$. From 1 st to 3 rd, each row respectively presents results for HadGEM, HdR_50km and HdR_25km

RCP8.5 scenario. There is not much difference between the two RCM simulations run at difference resolutions.

\subsection{Precipitation}

The projected precipitation changes in winter and summer under RCP8.5 at the end of the century simulated by HadGEM, HdR $550 \mathrm{~km}$ and HdR_25km are presented in Fig. 12. As shown in the figure, changes in DJF are similar among all three simulations, characterized by a significant increase over North China and a decrease along the southeast coast and Southwest China. HadGEM projects greater increase in North China than the RCMs, while the RCM (HdR_50km) projects greater decrease over Southeast China (Fig. 12a, c, e). For JJA, the precipitation change shows an increase in West China which is similar in all of the three simulations; in the eastern part of China, HadGEM simulation projects an increase while HdR_50km indicates little change and HdR_25km suggests a mixture increase and decrease (Fig. 12b, d, f). In general, the magnitude of precipitation change is larger in DJF than JJA, especially over the western part of China.

Compared to the RCP8.5 scenario, precipitation changes projected under the RCP4.5 scenario are similar in spatial pattern and lower in magnitude (mostly in the range of $-10-50 \%$ ) (figures not shown). For example, relative to the present-day climate (1986-2005), the regional mean changes of the JJA precipitation at the end of the century in whole China are 12.8, 5.5, 5.9\% in HadGEM, HdR_50km and HdR _25km, respectively, under the RCP4.5 scenario, and 
(a) Chang of Temp., Ann, ${ }^{\circ} \mathrm{C}$

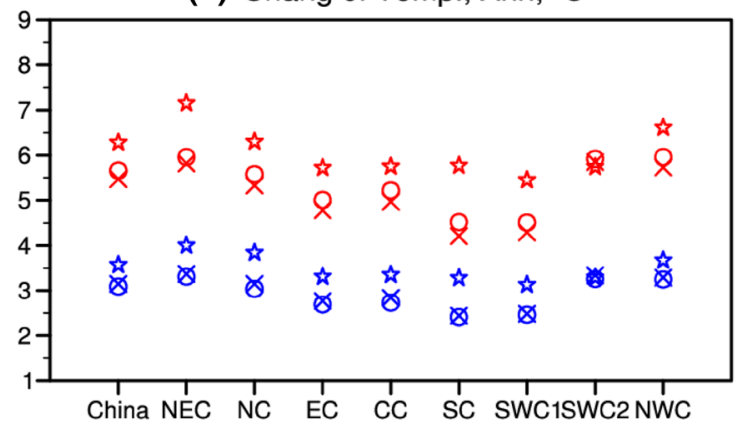

(c) Chang of Temp., DJF, ${ }^{\circ} \mathrm{C}$

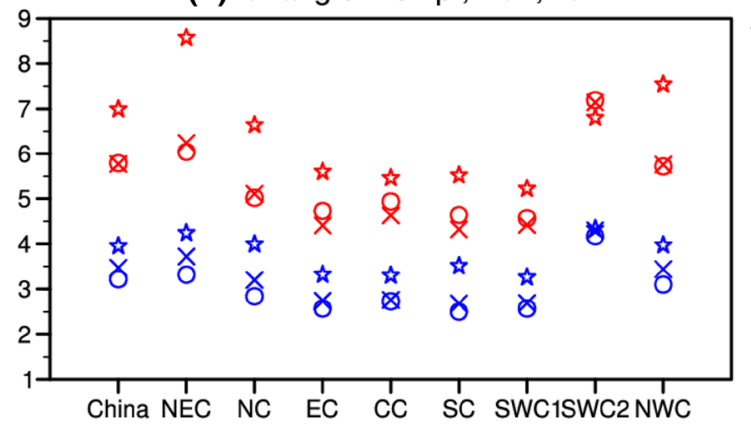

(e) Chang of Temp., JJA, ${ }^{\circ} \mathrm{C}$

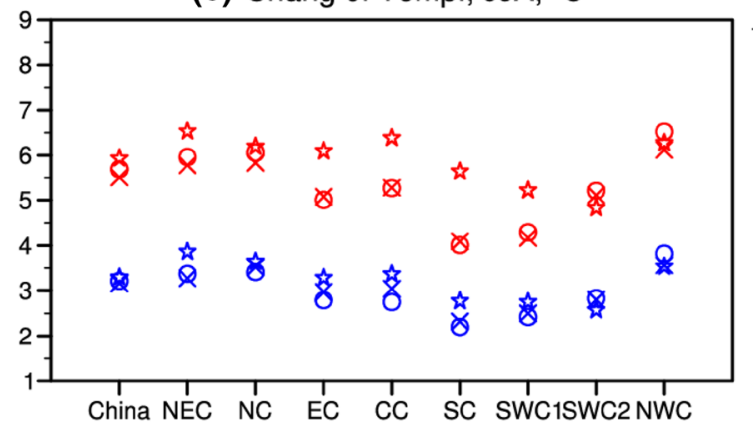

(b) Chang of Pre., Ann, \%

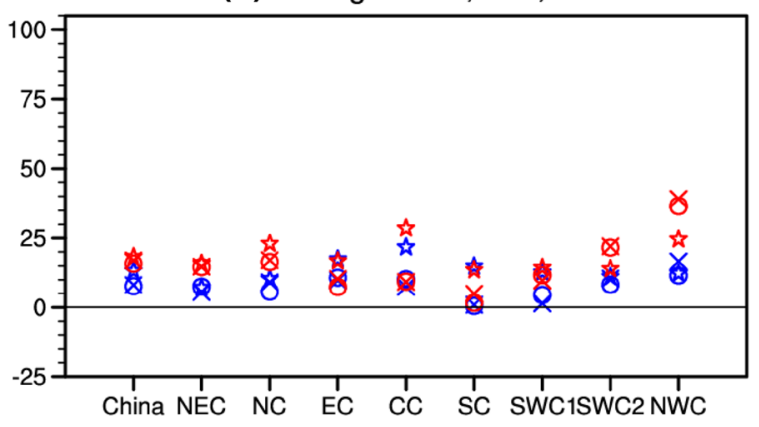

(d) Chang of Pre., DJF, \%

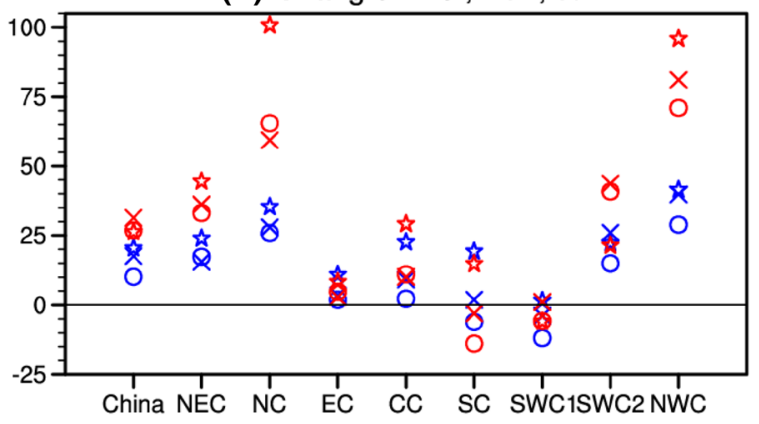

(f) Chang of Pre., JJA, \%

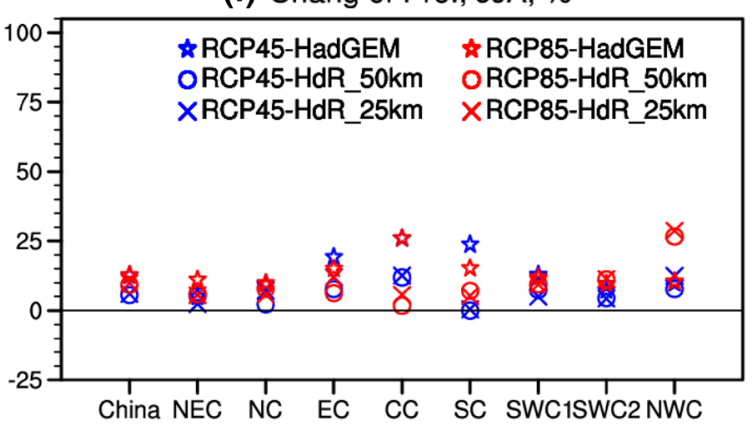

Fig. 11 Regional mean changes of temperature $\left(\mathbf{a}, \mathbf{c}, \mathbf{e},{ }^{\circ} \mathrm{C}\right)$ and precipitation $(\mathbf{b}, \mathbf{d}, \mathbf{f}, \%)$ at the end of twenty-first century under RCP4.5 (blue markers) and RCP8.5 scenarios (red markers)

are 13.1, 9.2, 9.9\% under the RCP8.5 scenario. Furthermore, contrary to the greater warming under RCP8.5 compared to RCP4.5, regional mean changes of precipitation averaged annually and during JJA under RCP8.5 do not show much difference in some sub-regions, such as $\mathrm{EC}$ and $\mathrm{SC}$, while in DJF, significant increase can be found in NC and NWC. On the other hand, precipitation changes are more significant in HadGEM and there is little difference between the two RCMs in most sub-regions in both DJF and JJA, which is similar to that of temperature.

\subsection{Climate extremes}

\subsubsection{Temperature-related extremes}

Changes of SU, TXx and TNn under the RCP8.5 scenario at the end of century are shown in Fig. 13. Together with the warming of mean climate, all of the three temperaturerelated indices will increase except SU over the Tibetan Plateau due to the much lower daily maximum temperature than the threshold in the definition there. Larger increase (exceeding 80 days) of SU can be found in Southwest China especially in Yunnan province in all three simulations and along the southeastern coast regions in HadGEM and HdR_50km simulations (Fig. 13a-c).

For TXx, it shows a large difference between the GCM and RCM simulations. In HadGEM, the increase of TXx is 
(a) Change of pre., DJF, RCP85, HadGEM, \%

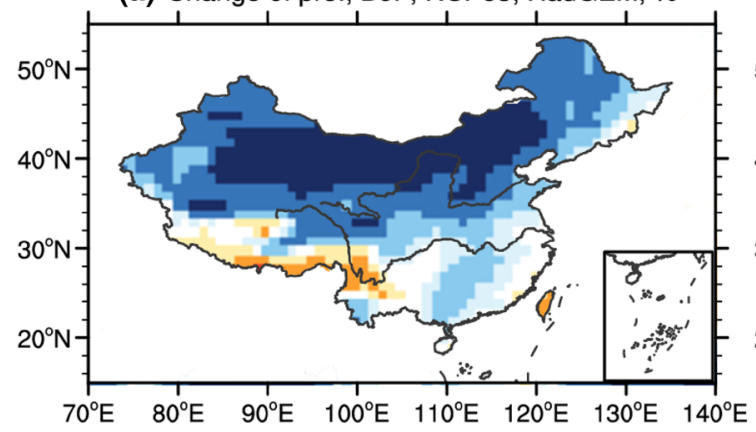

(c) Change of pre., DJF, RCP85, HdR_50km, \%

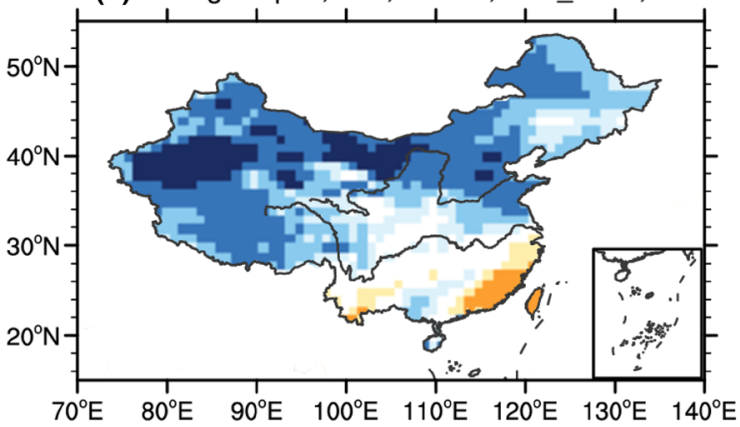

(e) Change of pre., DJF, RCP85, HdR $25 \mathrm{~km}, \%$

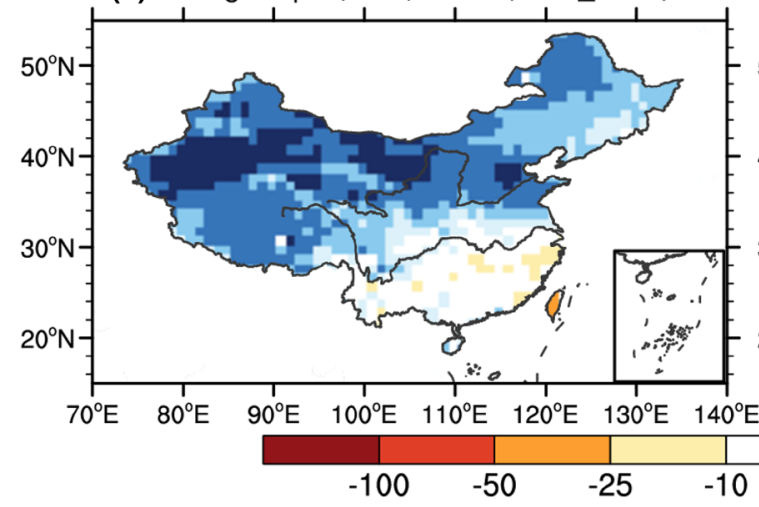

(b) Change of pre., JJA, RCP85, HadGEM, \%

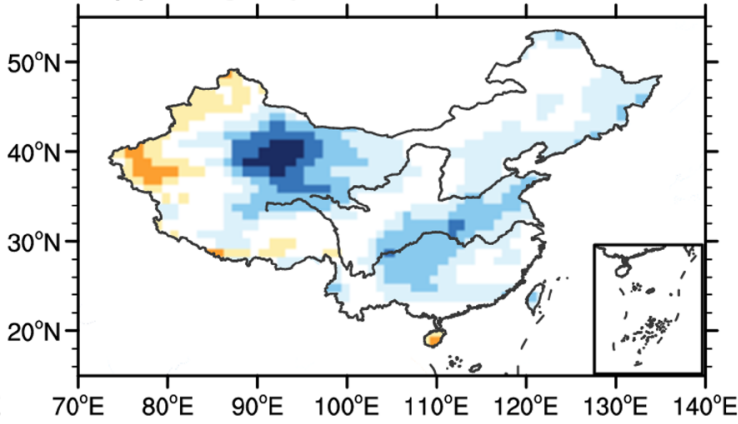

(d) Change of pre., JJA, RCP85, HdR_50km, \%

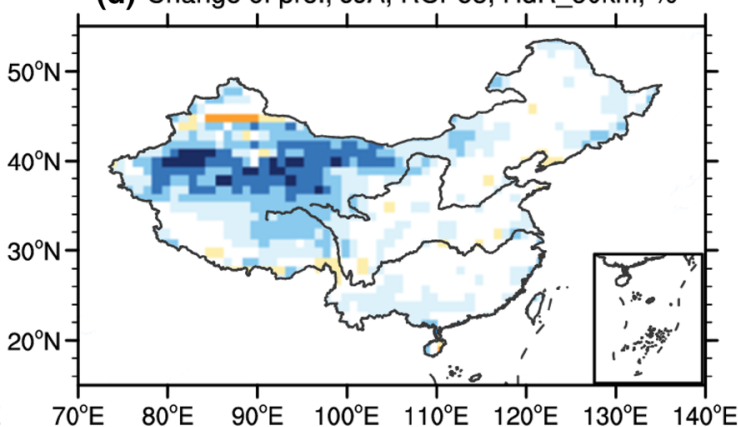

(f) Change of pre., JJA, RCP85, HdR $25 \mathrm{~km}, \%$

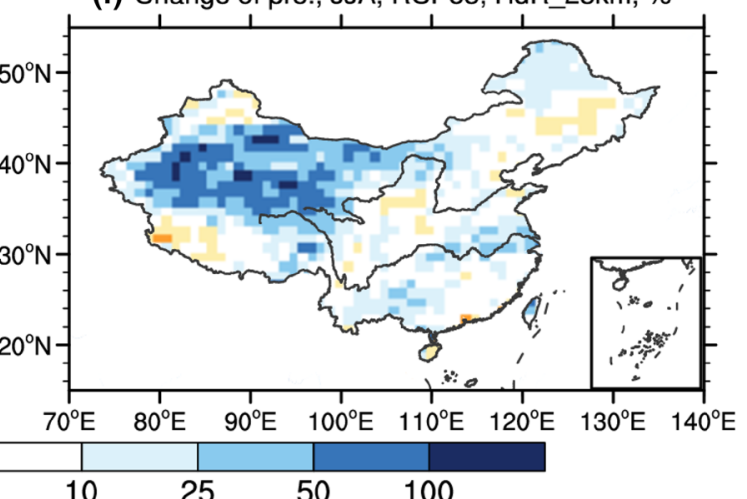

Fig. 12 Similar to Fig. 10, but for precipitation (unit \%)

projected to be greater than $7.5^{\circ} \mathrm{C}$ over most regions of East China and western regions of West China, and mainly in the range of $4-7.5^{\circ} \mathrm{C}$ over other regions; in the two RCM simulations, projected increases of $6-7.5^{\circ} \mathrm{C}$ can be found over Northeast, Northwest and North China, which are smaller than the increases in HadGEM. Of the two RCM simulations, greater warming can be found in HdR_50km over Northwest China (Fig. 13d-f).

In contrast to the changes of TXx, the spatial pattern of $\mathrm{TNn}$ is similar in all three simulations, with greater increase of above $7.5^{\circ} \mathrm{C}$ over the Northeast, Northwest and Tibetan Plateau and mostly in the range of $3.5-5.5{ }^{\circ} \mathrm{C}$ in other regions (Fig. 13g-i). In addition, with the improvement of resolution, all indices show more detailed spatial structure of changes.
Regional mean changes of temperature-related climate extremes under RCP4.5 and RCP8.5 scenario at the end of the century over China are shown in Table 3. In addition to the greater changes of SU, TXx, TNn under RCP8.5 compared to RCP4.5, other differences emerge. For example, SU and TXx changes in HadGEM simulation under both future scenarios are significantly greater than the RCMs, while for $\mathrm{TNn}$, the projected changes are similar among all three models, all around 4.0 and $7.0{ }^{\circ} \mathrm{C}$ under RCP4.5 and RCP8.5 scenario, respectively. As SU and TXx are both defined by daily maximum temperature, difference exhibited between the RCMs and driving GCM indicates that the model-related uncertainty in daily maximum temperature is relatively larger compared to that in daily minimum temperature. 
(a) Change of SU, HadGEM, RCP85, days

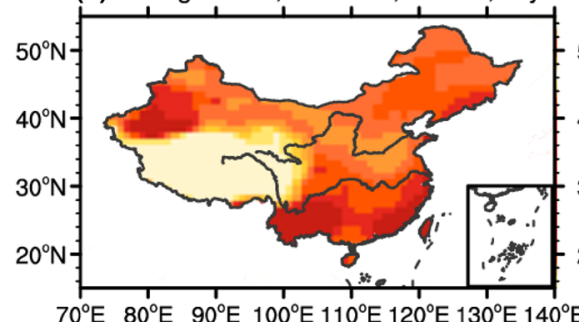

(b) Change of SU, HdR_50km, RCP85, days

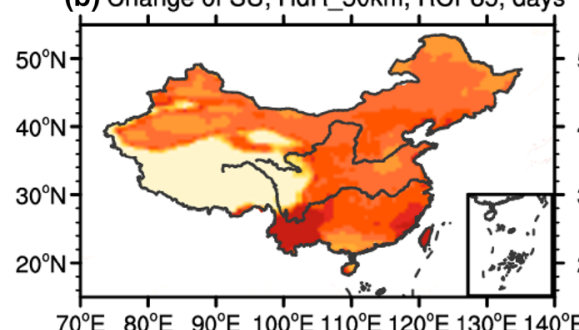

(c) Change of $\mathrm{SU}, \mathrm{HdR} 25 \mathrm{~km}, \mathrm{RCP} 85$, days

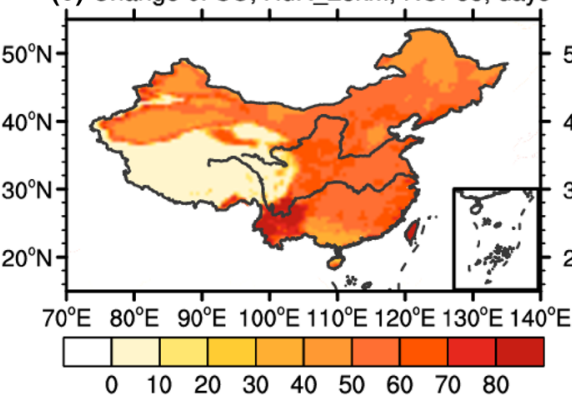

(d) Change of TXx, HadGEM, RCP85, ${ }^{\circ} \mathrm{C}$

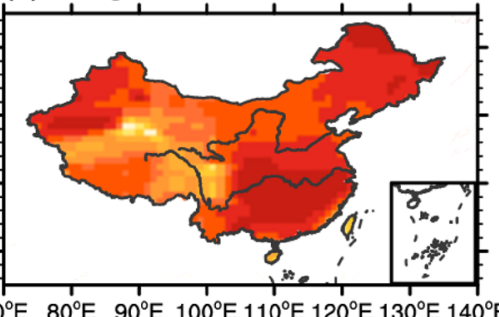

(e) Change of TXX, HdR $50 \mathrm{~km}, \mathrm{RCP} 85,{ }^{\circ} \mathrm{C}$

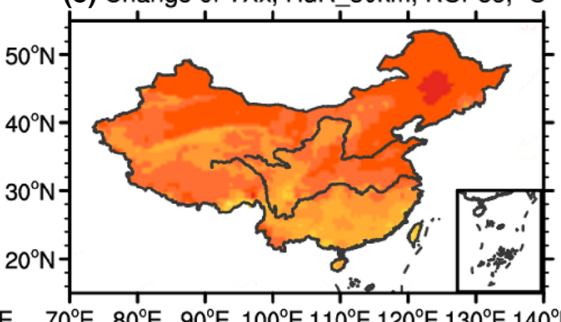

(f) Change of TXX, HdR $25 \mathrm{~km}, \mathrm{RCP} 85,{ }^{\circ} \mathrm{C}$

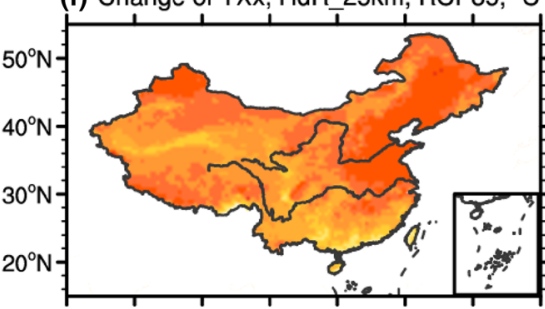

$70^{\circ} \mathrm{E} \quad 80^{\circ} \mathrm{E} \quad 90^{\circ} \mathrm{E} 100^{\circ} \mathrm{E} 110^{\circ} \mathrm{E} 120^{\circ} \mathrm{E} 130^{\circ} \mathrm{E} 140^{\circ} \mathrm{E}$

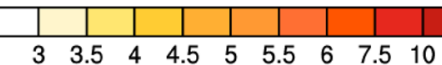

(g) Change of TNn, HadGEM, RCP85, ${ }^{\circ} \mathrm{C}$

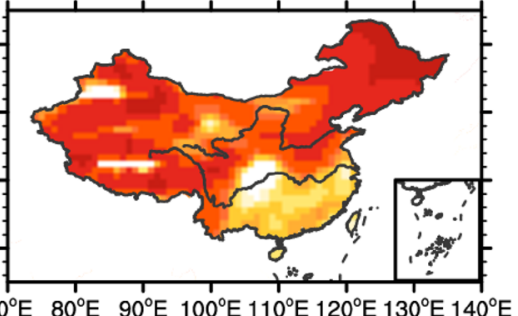

(h) Change of TNn, HdR 50km, RCP85, ${ }^{\circ} \mathrm{C}$

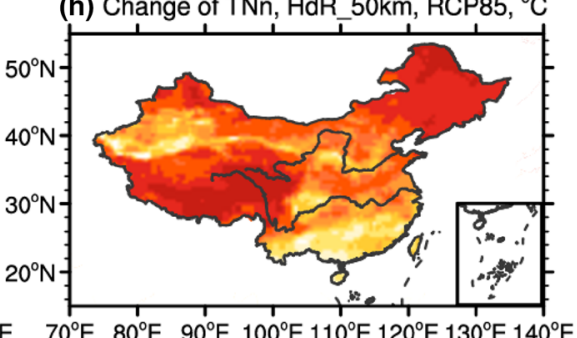

(i) Change of TNn, HdR_25km, RCP85, ${ }^{\circ} \mathrm{C}$

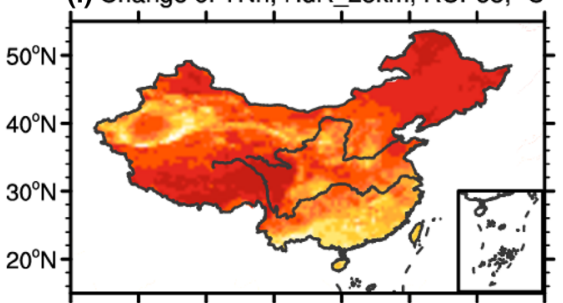

$70^{\circ} \mathrm{E} \quad 80^{\circ} \mathrm{E} \quad 90^{\circ} \mathrm{E} \quad 100^{\circ} \mathrm{E} 110^{\circ} \mathrm{E} 120^{\circ} \mathrm{E} 130^{\circ} \mathrm{E} 140^{\circ} \mathrm{E}$

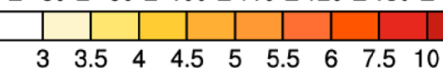

Fig. 13 Future changes of temperature-related climate extremes of $\mathrm{SU}\left(\mathbf{a}-\mathbf{c}\right.$, days), TXx $\left(\mathbf{d}-\mathbf{f},{ }^{\circ} \mathrm{C}\right), \mathrm{TNn}\left(\mathbf{g}-\mathbf{i}\right.$, $\left.{ }^{\circ} \mathrm{C}\right)$ at the end of twenty-first century under RCP8.5 scenario. From 1st to 3rd, each row respectively presents results for HadGEM, HdR_50km and HdR_25km

Table 3 Regional mean changes of temperature- and precipitation-related climate extremes under RCP4.5 and RCP8.5 scenarios at the end of the twenty-first century in HadGEM, HdR_50km and HdR_25km simulations

\begin{tabular}{|c|c|c|c|c|c|c|}
\hline & \multicolumn{2}{|c|}{ HadGEM } & \multicolumn{2}{|c|}{ HdR_50km } & \multicolumn{2}{|c|}{ HdR_25km } \\
\hline & RCP4.5 & RCP8.5 & RCP4.5 & RCP8.5 & RCP4.5 & RCP8.5 \\
\hline SU (days) & 30 & 49 & 24 & 46 & 24 & 42 \\
\hline $\mathrm{TXx}\left({ }^{\circ} \mathrm{C}\right)$ & 4.0 & 7.8 & 3.3 & 5.8 & 3.0 & 5.5 \\
\hline $\mathrm{TNn}\left({ }^{\circ} \mathrm{C}\right)$ & 3.8 & 7.0 & 3.9 & 7.0 & 4.2 & 7.2 \\
\hline CDD (\%) & -15 & -22 & -1 & -13 & -4 & -13 \\
\hline RX5day (\%) & 18 & 33 & 17 & 35 & 15 & 31 \\
\hline R95p (\%) & 49 & 86 & 29 & 67 & 33 & 75 \\
\hline
\end{tabular}

\subsubsection{Precipitation-related extremes}

Changes of CDD, RX5day and R95P under RCP8.5 scenario at the end of century are shown in Fig. 14. Overall, CDD would decrease in the west and increase in the southeast in all three simulations. The maxima decrease in West China with the value above $50 \%$ are simulated by HadGEM, while in the two RCM simulations, the magnitude is in the range of -50 to $-25 \%$. The increase in the south is similar between HadGEM and the RCMs. In addition, the magnitude of the CDD changes decreases from southeast to northwest in all three simulations, which contrasts that of soil moisture in the two RCM simulations (figures not shown). This findings indicates the probability of dry events will decrease in West China and increase in South China (Fig. 14a-c).

RX5day is projected to increase by all three simulations. With the value mostly in the range of $10-50 \%$, maxima increase is projected over the eastern regions of Northwest China in HadGEM, and in the western part of Northwest China in HdR_50km and HdR_25km. The spatial pattern of RX5day change in HdR_25km is very similar to that of HdR_50km, but the magnitude is much lower (Fig. 14d-f). 
(a) Change of CDD, HadGEM, RCP85, \%

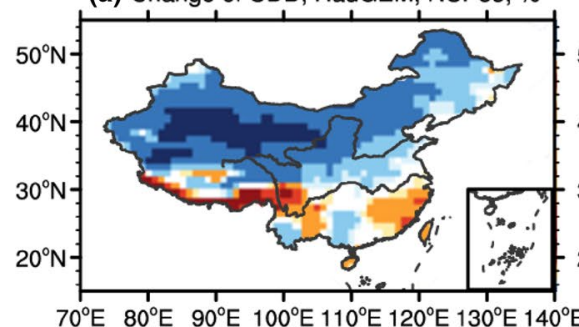

(d) Change of RX5day, HadGEM, RCP $85, \%$

(g) Change of R95P, HadGEM, RCP85, \%

(b) Change of CDD, HdR $50 \mathrm{~km}, \mathrm{RCP} 85, \%$

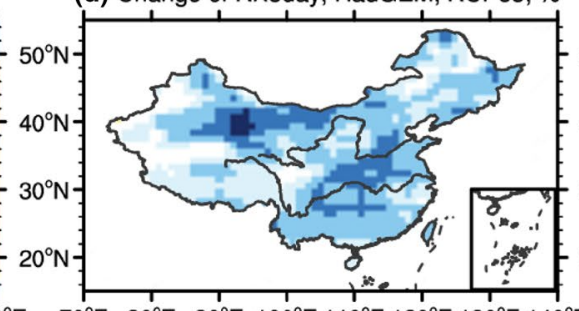

$70^{\circ} \mathrm{E} \quad 80^{\circ} \mathrm{E} 90^{\circ} \mathrm{E} 100^{\circ} \mathrm{E} 110^{\circ} \mathrm{E} 120^{\circ} \mathrm{E} 130^{\circ} \mathrm{E} 140^{\circ} \mathrm{E}$

(e) Change of RX5day, HdR_50km, RCP85, \%
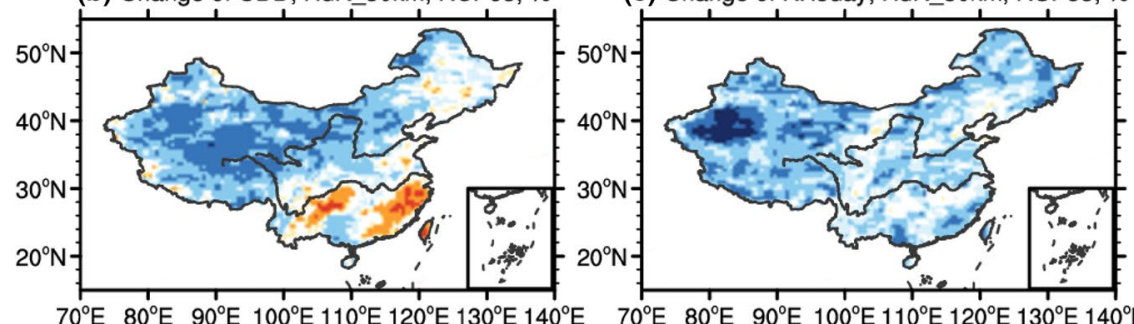

$=50^{\circ} \mathrm{N}-$

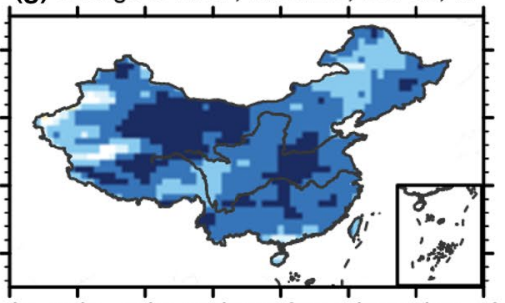

$70^{\circ} \mathrm{E} \quad 80^{\circ} \mathrm{E} \quad 90^{\circ} \mathrm{E} 100^{\circ} \mathrm{E} 110^{\circ} \mathrm{E} 120^{\circ} \mathrm{E} 130^{\circ} \mathrm{E} 140^{\circ} \mathrm{E}$

(h) Change of R95P, HdR_50km, RCP85, \%

(c) Change of CDD, HdR_25km, RCP85, \%
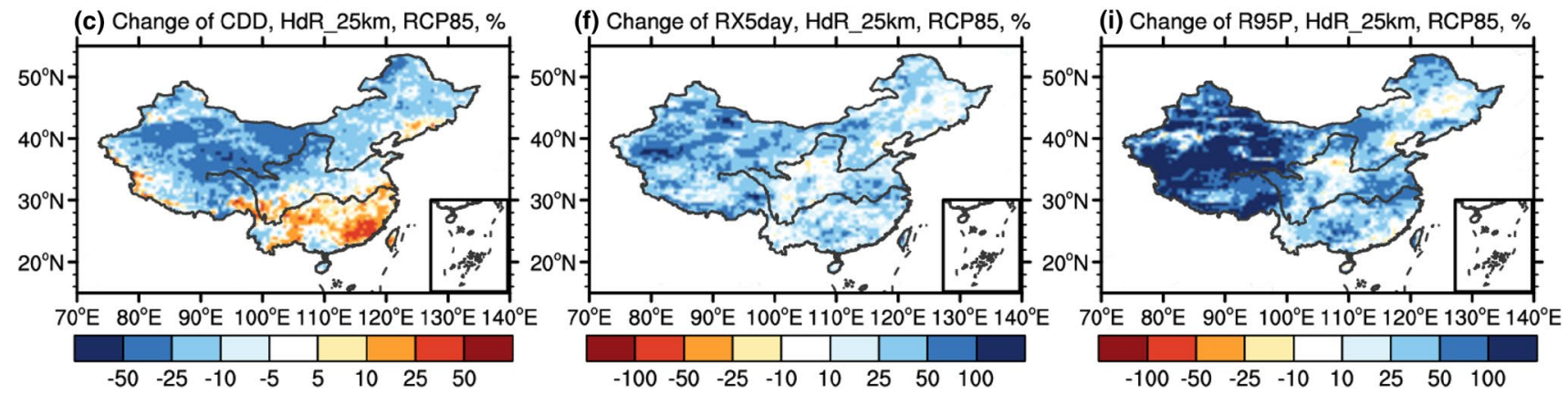

Fig. 14 Similar to Fig. 13, but for precipitation-related climate extremes of CDD (a-c, \%), RX5day (d-f, \%) and R95P (g-i, \%)

Significant increase of R95P (by more than 100\%) is projected for the western part of China by all three simulations. HadGEM also projects a significant increase in East China, by more than $50 \%$ across the board and by more than $100 \%$ over some areas, while RCM-projected increases are mostly in the range of $0-50 \%$ (Fig. $14 \mathrm{~g}-\mathrm{i}$ ).

Increase of RX5day and R95P in West China suggests that precipitation in the future would become significantly more extreme. In South China, increase of RX5day and R95P would coincide with an increase of CDD, suggesting both higher flood risk and higher drought risk for the future.

The two RCMs produce similar regional mean changes of precipitation-related climate extremes under the two scenarios, respectively. For example, the relative changes of CDD under RCP8.5 are both $-13 \%$, and changes of RX5day are both around $15 \%$ under RCP4.5. The RCMs-projected changes tend to be smaller/slower than the HadGEM-projected changes when/where significant differences between the two are found (Table 3).

\subsection{Daily precipitation intensity}

PDF distributions of daily precipitation intensity in whole China and its eight sub-regions in the present day and future climate are compared in Fig. 15. In all regions, the PDFs will have a rightward shift, which indicates that daily precipitation intensity will increase in the future. For example, in whole China, the HadGEM produce a maxima value of $\sim 100 \mathrm{~mm} /$ day in the present, while under RCP8.5, the value can be up to $180 \mathrm{~mm} /$ day. Similar results can also be found in HdR_50km and HdR_25km with an increase of $\sim 140$ and $\sim 150 \mathrm{~mm}$ /day from the present day to the end of the twentyfirst century, respectively. Compared to HadGEM, the RCMs produce a longer tail in both present day and future climate. When compared between the two RCMs, the PDF distributions are similar to each other but the higher resolution one shows a longer tail, which reflects the added value of RCMs and RCM resolution changes in capturing the fine-scale precipitation characteristics. In addition, the increase of daily precipitation intensity is in line with that of precipitationrelated extremes (e.g., RX5day and R95P). 

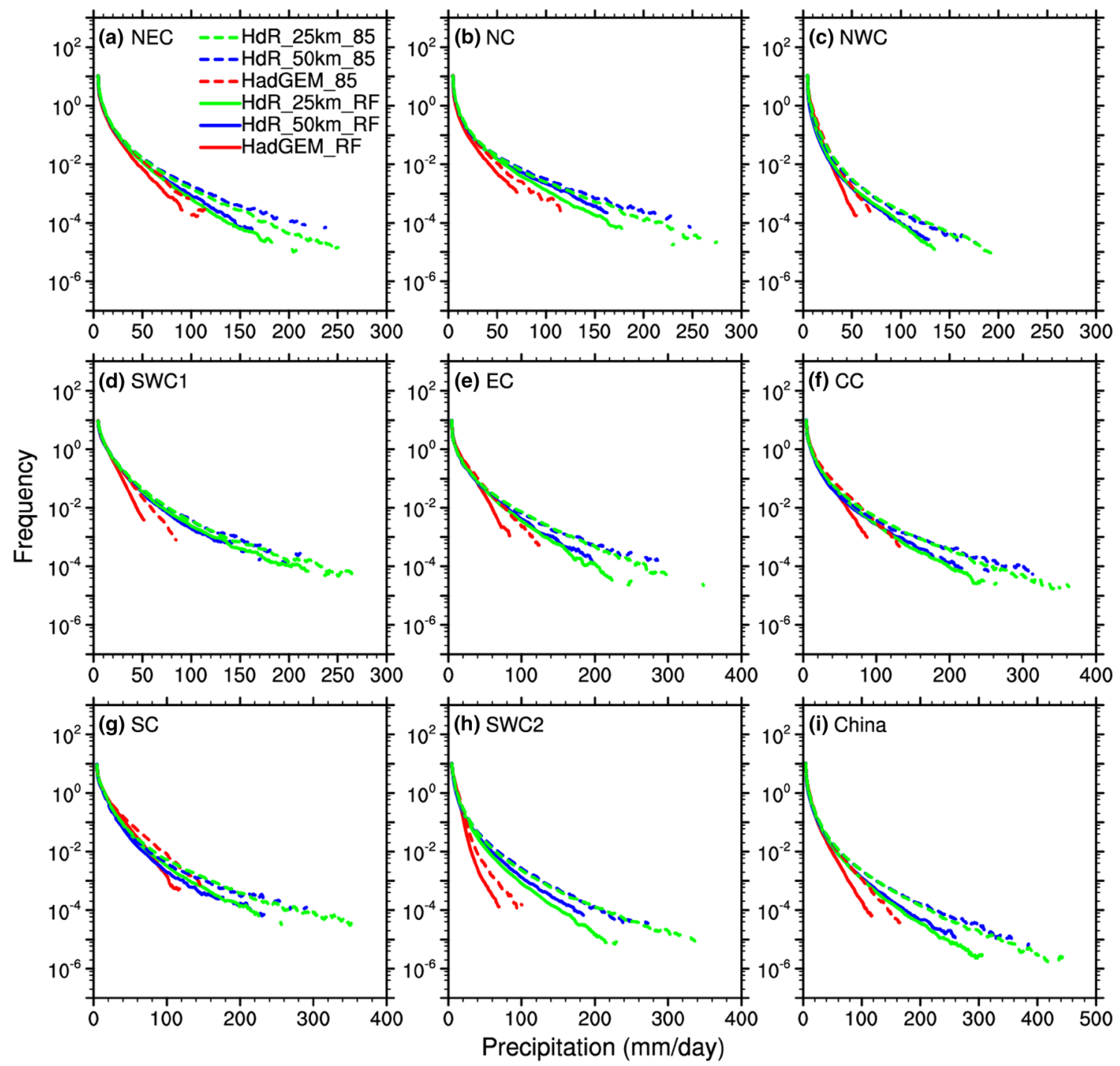

Fig. 15 Probability density function distributions of daily precipitation intensity ( $\mathrm{mm} /$ day) in whole China and its eight sub-regions in the present-day (solid line) and under RCP8.5 scenario (dash line)

\section{Conclusions and discussions}

In this paper, using different resolutions of the regional climate model RegCM4.4 driven by the global climate model HadGEM2-ES, we investigate future changes of temperature, precipitation and climate extremes at the end of the twenty-first century over mainland China with a focus on the high emission forcing scenario (RCP8.5). Our main conclusions and considerations can be summarized as follows:

1. The models can well reproduce the present day mean climate in temperature, precipitation and climate extremes. Compared to the driving global climate model, in addition to providing more detailed regional or local information, the RCMs also show a substantial improvement in simulating temperature and temperature-related extremes. Comparison between the two RCM simulations shows that the overall performance are similar, and the $50 \mathrm{~km}$ simulation performs slightly better for mean climate while the $25 \mathrm{~km}$ simulation performs slightly better for climate extremes.

2. The global and regional climate models exhibit some differences in the future climate change over China. The two RCM simulations project a similar level of future warming, which is lower than the HadGEM-projected warming in most sub-regions in both winter and summer, especially in NWC and NEC in winter under RCP8.5 scenario. Summer precipitation in HadGEM was projected to mostly increase in east part of China, whereas the two RCM experiments projected no clear change. But for regional mean changes of precipitation in summer, there is not much difference in most sub- 
regions among the three simulations, with exceptions over CC, SC and NWC. The pattern of precipitation change in DJF are similar in the two RCM simulations, but a little different from the global model in South China which presents increase and decrease in HadGEM and the two RCMs, respectively. In most sub-regions, the spatially averaged changes of precipitation in DJF projected by the two RCM simulations are similar, and are both lower than that in HadGEM.

3. Changes of SU and TNn in the three simulations especially in the two RCM simulations are very similar to each other. But for TXx simulation, there is some difference. For example, greater increase in HadGEM simulation can be found in South China where the relatively lower increase is presented in the two RCM simulations. The primary signal of the RX5day and R95P changes is an increase for all simulations, with the two RCMs sharing a similar spatial pattern. Projected CDD changes suggested dry events would become more severe in South China and less severe in North China.

Spatial resolution is an important consideration for climate simulations. The general notion has been that finer resolutions tend to improve model performance. In the context of regional climate modeling, finer resolution has frequently been cited as the advantage of RCMs over GCMs. Indeed, using the same regional climate model with different resolutions and driven by the same global climate model, the results show that increasing the RCM resolution from 50 to $25 \mathrm{~km}$ not only provide the finer detail in the spatial distribution of mean climate, but also produce a longer tail in the PDF distributions of daily precipitation intensity. These reflect the added value of high-resolution models. However, whether the added value in reproducing the present-day climate might result into more credible projections is still a problem open for discussion (Giorgi et al. 2016).

On the other hand, with the available observed dataset at one-degree resolution, the two RCMs with different spatial resolutions produce no significant performance improvement in present-day climate simulations. Little differences in the projected future changes are evident at 25 or $50 \mathrm{~km}$ resolutions, but both show differences compared to the driving GCM change patterns. In addition, for regional climate modeling, many physical parameterization schemes including convective scheme parameterization (Yang et al. 2015; Gao et al. 2016), cloud microphysics parameterizations, and aerosol emission factors and their interactions (Yan et al. 2015) are also important, especially for precipitation. Therefore, sensitivity experiments making use of the optimized parameters of convection scheme and/or different combinations of various model parameterizations are desirable to identify the best-performing model configuration (Yang et al. 2015; Gao et al. 2016).
Last but not least, large uncertainties exist in the simulation and projection of future climate changes, and are especially problematic at regional and local scales. Multi-model ensemble of climate projections is an important and effective way to reduce these uncertainties (Giorgi et al. 2009). Using regional climate model to conduct multiple relatively coarseresolution simulations driven with multiple GCMs and scenarios might be a better alternative than a single high-resolution simulation for obtaining more reliable information on climate change over China in the future, especially under the limitation of computer resources and given the need for future climate information for impact assessments.

Acknowledgements This study was jointly supported by the General Program of National Natural Science Foundation (41375104), the Climate Change Specific Fund of China (CCSF201731 and CCSF 201509), and the National Key Research and Development Program (2017YFA0605002 and 2016YFA0600704).

Open Access This article is distributed under the terms of the Creative Commons Attribution 4.0 International License (http://creativecommons.org/licenses/by/4.0/), which permits unrestricted use, distribution, and reproduction in any medium, provided you give appropriate credit to the original author(s) and the source, provide a link to the Creative Commons license, and indicate if changes were made.

\section{References}

Collins WJ, Bellouin N, Doutriaux-Boucher M et al (2011) Development and evaluation of an Earth-System Model-HadGEM2. Geosci Model Dev 4:1051-1075

Coppola E, Giorgi F (2010) An assessment of temperature and precipitation change projections over Italy from recent global and regional climate model simulations. Int J Climatol 30:11-32

Deque M, Jones RG, Wild M et al (2005) Global high resolution versus limited area model climate change projections over Europe: quantifying confidence level from PRUDENCE results. Clim Dyn 25:653-670

Emanuel KA (1991) A scheme for representing cumulus convection in large-scale models. J Atmos Sci 48:2313-2329

Frich P, Alexander LV, Della-Marta P, Gleason B, Haylock M, Klein Tank AMG, Peterson T (2002) Observed coherent changes in climatic extremes during the second half of the twentieth century. Clim Res 19:193-212. https://doi.org/10.3354/cr019193

Gao XJ, Zhao ZC, Ding YH, Huang RH, Giorgi F (2001) Climate change due to greenhouse effects in China as simulated by a regional climate model. Adv Atmos Sci 18:1224-1230

Gao XJ, Xu Y, Zhao ZC, Pal JS, Giorgi F (2006) On the role of resolution and topography in the simulation of East Asia precipitation. Theor Appl Climatol 86:173-185

Gao XJ, Shi Y, Song RY, Giorgi F, Wang YG, Zhang DF (2008) Reduction of future monsoon precipitation over China: comparison between a high resolution RCM simulation and the driving GCM. Meteorol Atmos Phys 100:73-86

Gao XJ, Shi Y, Zhang DF, Wu J, Giorgi F, Ji ZM, Wang YG (2012) Uncertainties in monsoon precipitation projections over China: results from two high-resolution RCM simulations. Clim Res $52: 213-226$ 
Gao XJ, Wang ML, Giorgi F (2013) Climate change over China in the 21st century as simulated by BCC_CSM1.1-RegCM4.0. Atmos Ocean Sci Lett 6:381-386

Gao XJ, Shi Y, Giorgi F (2016) Comparison of convective parameterizations in RegCM4 experiments with CLM as the land surface model over China. Atmos Ocean Sci Lett 9(4):246-254. https:// doi.org/10.1080/16742834.2016.1172938

Gao XJ, Shi Y, Han ZY, Wang ML, Wu J, Zhang DF, Xu Y, Giorgi F (2017) Performance of RegCM4 over major river basins in China. Adv Atmos Sci 34:441-445. https://doi.org/10.1007/ s00376-016-6179-7

Giorgi F, Marinucci R (1995) An investigation of the sensitivity of simulated precipitation to model resolution and its implication for climate studies. Mon Weather Rev 124:148-166

Giorgi F, Bi XQ, Pal JS (2004) Mean, interaanual variability and trends in a regional climate change experiment over Europe. II: climate change scenarios (2071-2100). Clim Dyn 23:839-858

Giorgi F, Jones C, Asrar GR (2009) Addressing climate information needs at the regional level: the CORDEX framework. WMO Bull 58:175-183

Giorgi F, Coppola E, Solmon F, Mariotti L, Sylla BM, Bi XQ (2012) RegCM4: model description and illustrative basic performance over selected CORDEX domains. Clim Res 52:7-29

Giorgi F, Coppola E, Raffaele F et al (2014) Changes in extremes and hydroclimatic regimes in the CREMA ensemble projections. Clim Change 125:39-51

Giorgi F, Torma C, Coppola E, Ban N, Schär C, Somot S (2016) Enhanced summer convective rainfall at Alpine high elevations in response to climate warming. Nat Geosci. https://doi.org/10.1038/ NGEO2761

Han ZY, Gao XJ, Shi Y, Wu J, Wang ML, Giorgi F (2015) Development of Chinese high resolution land cover for the RegCM4/CLM and its impact on regional climate simulation. J Glaciol Geocryol 37:857-866 (in Chinese)

Holtslag AA, De Bruijn EI, Pan HL (1990) A high resolution air mass transformation model for short-range weather forecasting. Mon Weather Rev 118:1561-1575

Huffman GJ, Adler RF, Morrissey MM, Bolvin DT, Curtis S, Joyce R, McGavock B, Susskind J (2001) Global precipitation at onedegree daily resolution from multi-satellite observations. J Hydrometeorol 2:36-50

Im ES, Ahn JB, Kwon WT, Giorgi F (2008) Multi-decadal scenario simulation over Korea using a one-way double-nested regional climate model system. Part II: future climate projection (20212050). Clim Dyn 30:239-254

IPCC (2013) Climate Change 2013: the Physical Science Basis. In: Stocker TF, Qin DH, Plattner GK, Tignor M and others (eds) Contribution of working Group I to the fifth assessment report of the intergovernmental panel on climate change. [Field CB, Barros VR, Dokken DJ et al (eds)]. Cambridge University Press, Cambridge

Jacob D, Petersen J, Eggert B et al (2014) EURO-CORDEX: new high-resolution climate change projections for European impact research. Reg Environ Change 14:563-578

Ji ZM, Kang SC (2013) Double-nested dynamical downscaling experiments over the Tibetan Plateau and their projection of climate change under two RCP scenarios. J Atmos Sci 70:1278-1290

Jiang DB, Wang HJ, Lang XM (2005) Evaluation of East Asian climatology as simulated by seven coupled models. Adv Atmos Sci 22:479-495

Jones CD, Hughes JK, Bellouin N et al (2011) The HadGEM2-ES implementation of CMIP5 centennial simulations. Geosci Model Dev 4:543-570

Karl TR, Nicholls N, Ghazi A (1999) CLIVAR/GCOS/WMO workshop on indices and indicators for climate extremes: workshop summary. Clim Change 42:3-7
Kendon EJ, Roberts NM, Senior CA, Roberts MJ (2012) Realism of rainfall in a very high-resolution regional climate model. J Clim 25:5791-5806

Kiehl JT, Hack JJ, Bonan GB, Boville BA, Williamson DL, Rasch PJ (1998) The national center for atmospheric research community climate model: CCM3. J Clim 11:1131-1149

Leung LR, Qian Y (2003) The sensitivity of precipitation and snowpack simulations to model resolution via nesting in regions of complex terrain. J Hydrometeorol 4:1025-1043

Meehl GA, Covey C, Delworth T et al (2007) The WCRP CMIP3 multi-model dataset: a new era in climate change research. B Am Meteorol Soc 88:1383-1394

Moss RH, Edmonds JA, Hibbard KA et al (2010) The next generation of scenarios for climate change research and assessment. Nature 463:747-756

Oleson KW, Niu GY, Yang ZL et al (2008) Improvements to the community land model and their impact on the hydrological cycle. J Geophys Res 113:G01021. https://doi.org/10.1029/2007JG000563

Pal JS, Small EE, Eltahir EA (2000) Simulation of regional-scale water and energy budgets: representation of subgrid cloud and precipitation processes within RegCM. J Geophys Res 105:29579-29594

Qian Y, Leung RL (2007) A long-term regional simulation and observations of the hydroclimate in China. J Geophys Res 112:D14104

Rojas M (2006) Multiply nested regional climate simulation for southern South America: sensitivity to model resolution. Mon Weather Rev 134:2208-2223

Shen Y, Xiong AY (2015) Validation and comparison of a new gaugebased precipitation analysis over mainland China. Int J Climatol. https://doi.org/10.1002/joc.4341

Tang JP, Zhao M, Su BK (2007) The effects of model resolution on the simulation of regional climate extreme events. Acta Meteorol Sin 21:129-140

Taylor KE (2001) Summarizing multiple aspects of model performance in a single diagram. J Geophys Res 106:7183-7192

Taylor KE, Stouffer BJ, Meehl GA (2012) An overview of CMIP5 and the experiment design. B Am Meteorol Soc 93:485-498. https:// doi.org/10.1175/BAMS-D-11-00094.1

Torma C, Coppola E, Giorgi F, Bartholy J, Pongracz R (2010) Validation of a high-resolution version of the regional climate model RegCM3 over the Carpathian Basin. J Hydrometeorol 12:84-100

Torma C, Giorgi F, Coppola E (2015) Added value of regional climate modeling over areas characterized by complex terrain-precipitation over the Alps. J Geophys Res 120:3957-3972

Wu J, Gao XJ (2013) A gridded daily observation dataset over China region and comparison with the other datasets. Chin J Geophys 56:1102-1111 (in Chinese)

Wu J, Gao XJ, Shi Y, Giorgi F (2011) Climate change simulation over Xinjiang region in 21 st century by a high resolution RCM. J Glaciol Geocryol 33:479-487 (in Chinese)

Xie PP, Yatagai A, Chen MY, Yang S (2007) A gauge-based analysis of daily precipitation over East. Asia J Hydrol 8:607-626

Xu Y, Gao XJ, Shen Y, Xu CH, Shi Y, Giorgi F (2009) A daily temperature dataset over China and its application in validating a RCM simulation. Adv Atmos Sci 26:763-772

Xu Y, Gao XJ, Giorgi F (2010) Upgrades to the reliability ensemble averaging method for producing probabilistic climate-change projections. Clim Res 41:61-81

Xu Y, Wu J, Shi Y, Zhou BT, Li RK, Wu J (2015) Change in extreme climate events over China based on CMIP5. Atmos Ocean Sci Lett 8:185-192

Yan HP, Qian Y, Zhao C, Wang HL, Wang MH, Yang B, Liu XH, Fu $\mathrm{Q}$ (2015) A new approach to modeling aerosol effects on East Asian climate: parametric uncertainties associated with emissions, cloud microphysics, and their interactions. J Geophys Res 120:8905-8924. https://doi.org/10.1002/2015JD023442 
Yang B, Zhang YC, Qian Y, Huang AM, Yan HP (2015) Calibration of a convective parameterization scheme in the WRF model and its impact on the simulation of East Asian summer monsoon precipitation. Clim Dyn 44:1661-1684. https://doi.org/10.1007/ s00382-014-2118-4

Yu ET, Wang HJ, Sun JQ (2011) A quick report on a dynamical downscaling simulation over China using the nested model. Atmos Ocean Sci Lett 3:325-329

Yu ET, Sun JQ, Chen HP, Xiang WL (2015) Evaluation of a highresolution historical simulation over China: climatology and extremes. Clim Dyn 45:2013-2031. https://doi.org/10.1007/ s00382-014-2452-6
Zhang XB, Alexander L, Hegerl GC, Jones P, Tank A, Peterson TC, Trewin B, Zwiers FW (2011) Indices for monitoring changes in extremes based on daily temperature and precipitation data. WIREs Clim Change 2:851-870. https://doi.org/10.1002/wcc.147

Zou LW, Zhou TJ (2013) Near future (2016-40) summer precipitation changes over China as projected by a regional climate model (RCM) under the RCP8.5 emissions scenario: Comparison between RCM downscaling and the driving GCM. Adv Atmos Sci 30:806-818 